\title{
Ligand Migration and Binding in the Dimeric Hemoglobin of Scapharca inaequivalvis
}

\author{
Karin Nienhaus ${ }^{\ddagger},{ }^{*}$, James E. Knapp $\S, \|,{ }^{*}$, Pasquale Palladino $\ddagger$, William E. Royer Jr.§, and G. \\ Ulrich Nienhaus $\$, \perp$ \\ ¥Institute of Biophysics, University of Ulm, 89069 Ulm, Germany \\ $\S$ Department of Biochemistry and Molecular Pharmacology, University of Massachusetts Medical School, \\ 364 Plantation St., LRB 921, Worcester, MA 01605, USA \\ $\perp$ Department of Physics, University of Illinois at Urbana-Champaign, 1110 West Green Street, Urbana, IL \\ 61801, USA
}

\section{Abstract}

Using Fourier transform infrared (FTIR) spectroscopy combined with temperature derivative spectroscopy (TDS) at cryogenic temperatures, we have studied CO binding to the heme and CO migration among cavities in the interior of the dimeric hemoglobin of Scapharca inaequivalvis ( $\mathrm{HbI})$ after photodissociation. By combining these studies with $\mathrm{x}$-ray crystallography, three transient ligand docking sites were identified: a primary docking site B in close vicinity to the heme iron, and two secondary docking sites $\mathrm{C}$ and $\mathrm{D}$ corresponding to the $\mathrm{Xe} 4$ and $\mathrm{Xe} 2$ cavities of myoglobin. To assess the relevance of these findings for physiological binding, we also performed flash photolysis experiments on $\mathrm{HbICO}$ at room temperature and equilibrium binding studies with dioxygen. Our results show that the $\mathrm{Xe} 4$ and $\mathrm{Xe} 2$ cavities serve as transient docking sites for unbound ligands in the protein, but not as way stations on the entry/exit pathway. For HbI, the so-called histidine gate mechanism proposed for other globins appears as a plausible entry/exit route as well.

The globin superfamily of proteins includes vertebrate hemoglobins $(\mathrm{Hb})$, vertebrate myoglobins $(\mathrm{Mb})$, invertebrate globins, plant globins, and bacterial and fungal flavohemoproteins (1). These proteins all bind oxygen and a variety of other small molecules at the central iron of a heme group enwrapped by the polypeptide chain in its characteristic 'globin' fold. Yet they are structurally highly diverse, ranging in size from the small monomeric mini-hemoglobin of the nemertean worm Cerebratulus lacteus with only 109 amino acid residues (2) to the giant erythrocruorin protein found in the annelid Lumbricus terrestris that consists of 144 hemoglobin subunits held together by 36 linker proteins (3). Globins perform a multitude of tasks in biological systems, including oxygen storage and transport, NO scavenging, enzyme action and small-molecule sensor function $(4,5)$.

The monomeric $\mathrm{Mb}$ is arguably the best studied member of the globin family. For many years, $\mathrm{Mb}$ has served as a model system for protein structural dynamics (6-13). A surprising complexity was discovered in its seemingly simple ligand binding reaction, which involves

\footnotetext{
Address correspondence to G. Ulrich Nienhaus, Institute of Biophysics, University of Ulm, 89069 Ulm, Germany, Tel.: +49 731 5023050, Fax.: +49 731 5023059, Email: uli@uiuc.edu.

Current Address: Department of Biochemistry and Molecular Biology, University of Texas, Medical Branch at Galveston, 301 University Blvd, Galveston, TX 77551-1055, USA

*The first two authors contributed equally.

${ }^{\dagger}$ G.U.N. was supported by the Deutsche Forschungsgemeinschaft (grant Ni 291/3) and the Fonds der Chemischen Industrie. W.E.R. was supported by the National Institutes of Health (grants DK43323 and GM66756).
} 
protein relaxations and fluctuations as well as ligand diffusion within the protein. Sophisticated biophysical experiments, notably x-ray structure analysis (14-20), optical and infrared spectroscopy (21-29) applied over wide ranges in time and temperature and on a large number of genetically modified Mbs have led to a detailed picture of ligand binding in this protein. In our laboratory, we have focused on Fourier transform infrared (FTIR) cryospectroscopy to study the migration of carbon monoxide (CO) among cavities within the protein interior, using the $\mathrm{CO}$ molecule as a sensitive probe of the local environment (27-31). At physiological temperature, these cavities serve as transient ligand docking sites so that the ligand shuttles back and forth among the docking sites within the protein after dissociation from the heme iron. Thereby, the probability of immediate rebinding is decreased and escape from the protein is enhanced. No permanent channel exists in the molecular structure of $\mathrm{Mb}$ that connects the active site to the outside, but a short channel can open between the heme pocket and the solvent upon rotation of the imidazole side chain of the distal histidine, His-64 (E7; all secondary structure assignments indicate the homologous positions in helices A - H of Mb) $(32,33)$. Solid evidence supporting ligand exit via the histidine gate has recently been provided by time resolved x-ray crystallography (20).

Ligand binding to hemoglobins is significantly more complex due to the additional effects of cooperativity between subunits $(34,35)$. Because of its simple, dimeric structure, hemoglobin $\mathrm{I}(\mathrm{HbI})$ from the blood clam Scapharca inaequivalvis has served as a paradigm to elucidate the structural and dynamic aspects of cooperative ligand binding in heme proteins (36-46). In contrast to the large quaternary rearrangements observed in the tetrameric human hemoglobin (47), the allosteric transition from the high-affinity R state to the low-affinity $\mathrm{T}$ state in $\mathrm{HbI}$ involves mainly tertiary structure changes, including a movement of residue Phe-97 (F4) from the subunit interface into the proximal heme pocket (36), reorganization of an interfacial water cluster (40) and relocation of the heme groups toward the subunit interface (39). Another striking difference is found in the mutual arrangement of the subunits. In human hemoglobin, the subunits are linked via helices $\mathrm{G}$ and $\mathrm{H}$ and corners $\mathrm{CD}$ and FG, whereas the HbI dimer interface is formed mainly by contacts between the E and F helices of the subunits (48). Due to this assembly, which is also observed in the echinoderm Caudina $\mathrm{HbD}$ and the giant hemoglobin of Lumbricus terrestris (49), the important distal histidine residue, His-69 (E7) in $\mathrm{HbI}$, is located in the interface (48), which raises the intriguing question if ligands can still exit the protein via the histidine gate.

Whereas the structural changes associated with the R-T transition of $\mathrm{HbI}$ have been studied in great detail, issues of ligand migration pathways have as yet gained little attention. Therefore, we have chosen to investigate $\mathrm{CO}$ ligand dynamics within $\mathrm{HbI}$ with a similar strategy as for $\mathrm{Mb}$, namely by combining x-ray crystallography and FTIR cryospectroscopy (27-30). A series of mutants was prepared to modify protein-ligand interactions, based on the experience gained from earlier studies on $\mathrm{Mb}$ (28). Voluminous residues were introduced to (i) directly block putative transient ligand docking sites (I25W), (ii) to occlude possible migration pathways to these sites (H69V-I114M, I114F) or (iii) to transform a possible docking site into a more efficient ligand trap (M37F). Furthermore, replacing His-69 modifies the active site structure, including the accessibility of the distal pocket from the EF interface (H69Q, H69L, H69V-

I114M). Mutant F97Y remains in the R-state conformation even in the unligated form and was, therefore, also included to explore possible influences of the allosteric transition on ligand migration and binding (36). The effects of these mutations on physiological ligand binding were examined by using flash photolysis and equilibrium tonometry at ambient temperature. 


\section{EXPERIMENTAL PROCEDURES}

\section{Protein Expression, Purification and Crystallization}

Site-directed mutagenesis was performed using the Quikchange mutagenesis kit (Stratagene, La Jolla, CA), with oligonucleotide primers encoding for the desired mutation. The mutant proteins were expressed in E. coli and purified according to the protocol established for recombinant wild-type $\mathrm{HbI}$ (50). Crystals of H69V-I114M HbICO, deoxy H69V-I114M, and deoxy M37F were grown in $2.6 \mathrm{M}$ sodium and potassium phosphate buffer, $\mathrm{pH}$ 8.5. CO-ligated I25W and M37F crystals were obtained from $2.4 \mathrm{M}$ sodium and potassium phosphate buffer, $\mathrm{pH} 7.5$, as described (48). A few I25W crystals were rinsed in stabilizing solution (2.4 M sodium and potassium phosphate, $\mathrm{pH} 7.5$ ) and coated with paratone $\mathrm{N}$ oil before xenon was introduced at pressures between 200 and 400 psi within a xenon chamber (Hampton Research, Aliso Viejo, CA). The crystals were frozen in liquid nitrogen immediately after xenon exposure.

\section{Structure Determination}

X-ray diffraction data sets of I25W HbICO, M37F HbICO and unligated (deoxy) M37F HbI were collected with a R-AXIS IV detector system (Rigaku Americas, The Woodlands, TX) and a RU200 rotating anode x-ray generator with Osmic mirrors (Rigaku) as the X-ray source. The data sets of H69V-I114M with and without bound CO were measured with a Mar 345 image plate detector system (marUSA Inc., Evanston, IL) and an R 2 rotating anode generator and Osmic mirrors (Rigaku). The data of I25W were collected at $100 \mathrm{~K}$ whereas the other data sets were collected at room temperature. Each data set was processed and scaled with the HKL suite of programs (51) and converted to structure factors with the program TRUNCATE of the $\mathrm{CCP} 4$ package (52). The models of wild-type $\mathrm{HbI}$ in the CO-ligated and deoxy forms (protein data bank (PDB) accession codes $3 \mathrm{SDH}$ and $4 \mathrm{SDH}$, respectively) were used as search models. Each structure was refined with the program CNS (53) with manual fitting with the program $\mathrm{O}$ (54). The atomic coordinates of the CO-ligated forms of I25W (2R4Z), M37F (2R4W), and H69V-I114M (2R4X) and deoxy M37F (2Z85) and H69V-I114M (2R4Y) have been deposited in the PDB; the accession codes are given in parentheses.

Diffraction data on the xenon-exposed I25W crystals were collected at the Argonne National Laboratory on beamline BM 14C (BioCARS) at the Advanced Photon Source (APS) using an ADSC CCD detector (Area Detector Systems Corporation, Poway, CA). Data were processed with the HKL2000 package and scaled with Scalepack (51). Xe atoms were located in the $\mathrm{Fo}_{\mathrm{I} 25 \mathrm{~W}}-\mathrm{FO}_{\mathrm{I}} 25 \mathrm{~W} / \mathrm{Xe}$ difference maps. The model was refined with a combination of CNS (53) and Shelx (55), with a round of manual intervention in between. The structure of I25W/Xe $\mathrm{HbICO}$ has been deposited in the PDB with accession code 2Z8A. The crystal structure of I114F was previously deposited under the accession code 1 JWN. Figures 1-3 were prepared with the computer programs Bobscript (56) and Raster3D (57). All crystal parameters and data collection and refinement statistics are compiled in Table 1.

\section{Fourier Transform Infrared (FTIR) Spectroscopy}

Lyophilized dimeric HbI from Scapharca inaequivalvis was dissolved in cryosolvent (75\%/ $25 \%$ (v/v) glycerol/phosphate buffer) to a final concentration of $\sim 20 \mathrm{mM}$, stirred under CO for $1 \mathrm{~h}$, and reduced with a two-fold molar excess of an anaerobically prepared sodium dithionite solution. FTIR transmission spectra were collected between 1800 and $2400 \mathrm{~cm}^{-1}$ at a resolution of $2 \mathrm{~cm}^{-1}$ using a FTIR spectrometer equipped with an InSb detector (IFS 66v/S, Bruker, Karlsruhe, Germany). Sample loading and cryospectroscopy equipment have been described previously $(28-30,58)$. 
Temperature derivative spectroscopy (TDS) is a two-dimensional spectroscopic method that employs temperature as a second dimension for studying thermally activated rate processes governed by enthalpy barrier distributions (59-61). These distributions are universally observed in ligand binding to heme and other proteins at cryogenic temperatures and result from conformational heterogeneity $(6,62)$. Prior to TDS data acquisition, a non-equilibrium state is prepared at very low temperature $(<10 \mathrm{~K})$, and the relaxation of the sample back to equilibrium is subsequently recorded while the temperature is increased linearly in time over a few hours. In heme proteins, we generate the initial non-equilibrium state by photolysis with visible light, and afterwards, we raise the temperature (typically $5 \mathrm{mK} / \mathrm{s}$ ) in the dark and observe ligand rebinding using FTIR spectroscopy. The bench is synchronized with the temperature control so that an FTIR transmission spectrum, $I(v, T)$, is acquired every $200 \mathrm{~s}$ and thus every Kelvin. As the temperature increases, rebinding occurs sequentially with respect to the heights of the enthalpy barriers that have to be surmounted in this process. In the simplest form of the TDS data analysis, one assumes that a change in the integrated absorbance (spectral area) is solely due to recombination, and the absorbance change is set proportional to the rebinding population, $\Delta A(\mathrm{v}, \mathrm{T}) \propto \Delta N(v, T)$. However, infrared spectra have an intrinsic temperature dependence which can be accounted for by appropriate scaling $(31,63,64)$. The population changes between successive temperature steps are obtained by calculating absorbance difference spectra from transmission spectra at successive temperatures, $\Delta A(v, T)=\log [\mathrm{I}(\mathrm{v}$, $T-1 / 2 \mathrm{~K})-I(v, T+1 / 2 \mathrm{~K})]$, which approximates the (negative) derivative of the population with respect to temperature, $-\mathrm{d} N(T) / \mathrm{d} T$. For a simple two-state reaction controlled by an enthalpy barrier, the distribution of barriers in the ensemble, $g(H)$, can be extracted from this quantity. TDS data are conveniently represented as two-dimensional contour plots of $-\mathrm{d} N(T) /$ $\mathrm{d} T$ versus wavenumber and temperature, with black and red lines indicating an absorbance increase and decrease, respectively. Usually, we take a logarithmic spacing of the contour levels to emphasize small features.

\section{Ligand Binding at Ambient Temperature}

CO-ligated samples were prepared in $3 \times 1 \times 1 \mathrm{~cm}^{3}$ glass cuvettes sealed with a rubber septum. Lyophilized protein was dissolved at a final concentration of $\sim 10 \mu \mathrm{M}$ in $100 \mathrm{mM}$ sodium phosphate buffer, $\mathrm{pH} 8$, and 75\%/25\% glycerol/phosphate buffer, $\mathrm{pH} 8$, equilibrated with 5\% $\mathrm{CO} / 95 \% \mathrm{~N}_{2}$, followed by reduction with excess sodium dithionite solution. $\mathrm{CO}$ association rate coefficients were measured with our flash photolysis system which has been described elsewhere (28). To avoid problems due to photoselection and rotational tumbling (65), we ensured that the photolysis yield of the nanosecond Nd-YAG laser was $>98 \%$ in a single pulse. Up to five hundred transients were averaged for each kinetic trace. The absorption changes measured at $436 \mathrm{~nm}$ were scaled according to the peak Soret absorbance of the CO-ligated species. Because mutations are not expected to significantly change the heme extinction properties, this procedure thus compensates for slightly different protein concentrations.

Oxygen association equilibria were studied by tonometry as described by Knapp et al. (39). The oxygen affinity (in torr) denotes the partial pressure at which 50\% of the binding sites are occupied and the cooperativity (Hill coefficient) is given by the slope of the binding curve in the Hill plot.

\section{RESULTS AND DISCUSSION}

\section{Crystal Structures of I25W HbICO with and without Xenon}

Crystals of CO-ligated I25W are isomorphous with the corresponding wild-type crystals (Table 1). The R-state conformation of I25W HbICO is practically identical to that of R-state wildtype $\mathrm{HbICO}$, including the relative location of the heme groups within each subunit, the disposition of Phe-97, and the organization of the interfacial water network. Although 
tryptophan has a much larger side chain than isoleucine, the exchange at position 25 has essentially no effect on the structure near the active site because the indole moiety fits perfectly into the pre-existing cavity between the B, E, and G helices (Figure 1). The edge of the indole ring with its positive partial charge forms a cation-pi interaction with the face of the Trp-135 side chain carrying a negative partial charge. The Trp- 25 indole ring is flipped between the two subunits of the asymmetric unit, but the cation- $\pi$ interaction with Trp-135 is maintained. In both subunits, the Trp- 25 side chain resides in a very hydrophobic cavity formed by the side chains of Trp-22, Met-73, Leu-77, Ile-118, Val-121, and Leu-122.

In the structure of Xe-exposed I25W HbICO crystals, the Xe atoms are found in two specific locations within each subunit (Figure $1 B$ ). The highly (60 - 70\%) occupied site corresponds to the (second-most occupied) $\mathrm{Xe} 2$ site of $\mathrm{Mb}$ (66). It is bounded by the hydrophobic side chains of Leu-77, Phe-80, Phe-111, Trp-135, Leu-138, Val-139, and Val-142. The second, weakly (10 - 12\%) occupied site in I25W corresponds to the (most-occupied) Xe1 site of $\mathrm{Mb}$. The Xe atom is located adjacent to pyrrole ring $\mathrm{C}$ on the proximal side of the heme group, in a pocket defined by Phe-80, Phe-97, His-101, Phe-111, and Val-142.

\section{Crystal Structures of H69V-I114M}

Crystals of H69V-I114M in both the unligated and CO-ligated forms are isomorphous to unligated wild-type $\mathrm{HbI}$ (Table 1). The quaternary structure is essentially identical to the one of T-state wild-type $\mathrm{HbI}$, with the two quaternary states differing from each other by $0.3^{\circ}$ (the two quaternary states of wild-type $\mathrm{HbI}$ differ from each other by $3.3^{\circ}(48)$ ). The arrangement of Phe-97 and the water interface structure are in accord with the R-state conformation of the wild-type counterpart. However, the heme groups assume a position intermediate between the typical R-state and T-state positions, even in the absence of a ligand. Each heme plane is shifted slightly toward the distal side so that the Met-37-ligand interspace is only $3.2 \AA$ as compared to $3.5 \AA$ in wild-type HbICO. Val-69 does not interact with the ligand; its side chain is located $4 \AA$ from the bound CO. In comparison to the wild-type protein, the methionine residue at position 114 (G8) narrows the channel bordered by the side chains of Leu-36 (B9), Leu-73 (E11), and residue G8, which separates the distal pocket from the corner circumscribed by the $\mathrm{B}, \mathrm{E}$ and $\mathrm{G}$ helices. The closest packing distance between residues $\mathrm{G} 8$ and E11, which is 5.6 $\AA$ in wild-type HbI, is reduced to $4.0 \AA$ in the H69V-I114M mutant (Figure 2). Except for the positioning of the heme groups (see above), the structures of deoxy H69V-I114F and deoxy wild-type $\mathrm{HbI}$ are identical.

\section{Structural Features of M37F Hbl}

Crystals of CO-ligated M37F are isomorphous with those of wild-type HbICO (Table 1).

However, significant structural differences to wild-type $\mathrm{HbI}$ emerge upon closer inspection on both the proximal and distal sides of the heme group. In the A subunit (Figure 3A), the Phe-37 phenyl ring packs tightly against Leu-73 (closest packing distance $3.1 \AA$ ), which in turn pushes heme pyrrole $B$ towards the proximal pocket. In the B subunit (Figure $3 B$ ), the Phe-37 side chain packs against Phe-51 (closest packing distance $3.1 \AA$ ). This interaction causes the heme plane to tilt so that pyrrole ring $\mathrm{D}$ is pointed more towards the proximal pocket, while pyrrole ring B is rotated towards the distal pocket. Consequently, the cavity underneath pyrrole B is enlarged, allowing Phe-97 in a fraction of protein molecules to assume its T-state conformation, with the Phe-97 side chain in the proximal pocket. In both subunits, Phe-37 packs tightly against the bound $\mathrm{CO}$, with the edge of the phenyl ring located $2.8 \AA$ away from the ligand. The distance between the face of the Phe-37 phenyl ring and the edge of the His-69 imidazole ring is $3.1 \AA$. In the A subunit, Phe-37 partially blocks access to the BEG channel. In the unligated structure (Figure $3 C$ ), the Phe-37 side chain displays two conformations in both subunits. In the dominant conformation, the Phe-37 phenyl ring packs against Phe-51, whereas in the minor conformation (occupancy $20-30 \%$ ), the side chain occludes the binding site. 


\section{The Active Site of Wild-type Hbl}

Previous studies on Scapharca inaequivalvis $\mathrm{HbI}$ were mainly focused on elucidating the structural determinants of the allosteric behavior, whereas the molecular details of ligand association itself have as yet received less attention. Studies of ligand migration and binding in $\mathrm{HbI}$ are greatly aided by previous results from IR spectroscopy experiments on $\mathrm{MbCO}$, which exploited the $\mathrm{CO}$ stretching vibration as a reporter of the local electrostatic environment. Three CO bands can be distinguished at 1966,1945 and $1930 \mathrm{~cm}^{-1}$, they are denoted by $\mathrm{A}_{0}$, $A_{1}$ and $A_{3}$, respectively, and are associated with three subconformations, in which the distal histidine His-64 side chain is positioned in various ways so as to produce different electrostatic interactions with the bound $\mathrm{CO}$ ligand. In the $\mathrm{A}_{1}$ and $\mathrm{A}_{3}$ substates, the imidazole side chain is neutral and resides inside the distal pocket, whereas it is doubly protonated and pointed towards the solvent in the $\mathrm{A}_{0}$ substate $(67,68)$. After photodissociation, the $\mathrm{CO}$ ligand transiently occupies specific locations inside $\mathrm{Mb}$, the primary docking site $\mathrm{B}$ on top of heme pyrrole $\mathrm{C}$ (14-16) and secondary sites $C$ and $D$ that coincide with two of four hydrophobic cavities in the protein interior, labeled Xe4 and Xe1 for their ability to bind Xe (17-19,69). In each of these sites, the CO ligand gives rise to specific photoproduct spectra, with the stretching frequency fine-tuned by the vibrational Stark effect, the interaction of the $\mathrm{CO}$ infrared transition dipole with the electric field at the site $(31,63,70,71)$. Frequently, doublet bands are observed due to two discrete orientations of the CO.

The immediate distal pocket environment of the heme-bound ligand in $\mathrm{HbI}$ is shaped by Met-37 (B10) and His-69 (E7). The His-69-NeH is capable of forming a hydrogen bond with a dioxygen ligand (48). Met-37 in position B10 is rather uncommon. In vertebrate Hbs and Mbs, there is typically a leucine in this position; in many non-vertebrate globins, the B10 residue is either glutamine, phenylalanine or tyrosine (72). The $\mathrm{CO}$ stretching absorption as an extremely sensitive internal probe allows us to examine the conformation of these nearby residues. Therefore, the HbICO samples were cooled to $4 \mathrm{~K}$ in the dark and illuminated for $1 \mathrm{~s}$, which results in complete photodissociation of the $\mathrm{CO}$ ligands from the heme iron. FTIR absorbance difference spectra, $A=\log \left(I_{\text {dark }} / I_{\text {light }}\right)$, were calculated from transmission spectra, $I(v, T)$, taken before and after photolysis. The peak frequencies and fractional band areas (populations) of the $\mathrm{CO}$ stretching bands in the heme-bound and photodissociated species were determined from fits with multiple Gaussians; the best-fit parameters are compiled in Table 2.

At $4 \mathrm{~K}$, the spectrum of wild-type $\mathrm{HbICO}$ in cryosolvent at $\mathrm{pH} 7.2$ shows a predominant $(97 \%$ population) A substate band at $1948 \mathrm{~cm}^{-1}$ and a minor band at $1964 \mathrm{~cm}^{-1}$ (Figure $4 A$ ). Similar spectra are found for I25W, I114F and F97Y (Figure 4A), implying that a more distant point mutation does not affect the active site structure. The A band at $1948 \mathrm{~cm}^{-1}$ can be associated with the conformation seen in the high-resolution crystal structure of wild-type HbICO determined at $\mathrm{pH} 7.5$, in which the His-69 imidazole side chain resides within the distal heme pocket (48). The frequency of this band is similar to the one of the $A_{1}$ substate at $1945 \mathrm{~cm}^{-1}$ in $\mathrm{MbCO}$, which suggests that a weak hydrogen bond exists between His-69-N $\varepsilon \mathrm{H}$ and the $\mathrm{CO}$ oxygen $(68,73,74)$. For the H69Q HbICO mutant, we find an asymmetric band at 1957 $\mathrm{cm}^{-1}$ with broad tails that can be modeled by additional bands at $1945 \mathrm{~cm}^{-1}$ and $1971 \mathrm{~cm}^{-1}$, indicating that the glutamine side chain adopts different conformations and is also involved in hydrogen bonding interactions with the bound $\mathrm{CO}$.

Interestingly, the $\mathrm{A}_{1} / \mathrm{A}_{3}$ heterogeneity in $\mathrm{MbCO}$, which presumably arises from two slightly different positions of the distal histidine $(68,75)$, is entirely absent in wild-type HbICO. However, the M37F substitution causes a significant shift of the dominant A state band to a more $\mathrm{A}_{3}$-like frequency of $1939 \mathrm{~cm}^{-1}$; a second, smaller band is visible at $1965 \mathrm{~cm}^{-1}$. The low wavenumber of the band at $1939 \mathrm{~cm}^{-1}$ has frequently been reported for mutant Mbs with an aromatic residue at position $\mathrm{B} 10$ and arises from the interaction of the $\mathrm{CO}$ dipole with the positive partial charge provided by the edge of the aromatic ring $(58,74)$. 
Bands near $1965 \mathrm{~cm}^{-1}$ are typically observed when the $\mathrm{A}_{1}$-type interaction of the bound $\mathrm{CO}$ with the distal histidine is absent, for instance, after replacement by aliphatic residues (68, 74). His-69 replacement by the aliphatic leucine or valine in HbICO produces stretching frequencies of 1971 and $1977 \mathrm{~cm}^{-1}$, respectively (Table 2). These frequencies are even higher than in the corresponding $\mathrm{Mb}$ mutants $(73,74)$. The presence of a negative partial charge near the $\mathrm{CO}$ oxygen, for example, from a lone pair of the Met-37 sulfur atom could explain this blue shift.

The minority species of wild-type $\mathrm{HbICO}$ (3\% population) represented by the high-frequency band at $1964 \mathrm{~cm}^{-1}$ resembles the $\mathrm{A}_{0}$ substate of $\mathrm{MbCO}$, associated with a CO band at 1965 $\mathrm{cm}^{-1}$. This conformation grows in $\mathrm{MbCO}$ toward low $\mathrm{pH}$ because of protonation of the imidazole ring of the distal histidine with a pK of 4.5 (68), which is pointed toward the solvent for better charge solvation (67). For HbICO, we also observe an enhanced fraction (40\%) of the $1964 \mathrm{~cm}^{-1}$ band (in cryosolvent, $\mathrm{pH} 4$ ) at room temperature. However, upon cooling to 4 $\mathrm{K}$, both A bands merge into a broad band at $1955 \mathrm{~cm}^{-1}$, with a weak shoulder at $1974 \mathrm{~cm}^{-1}$ (Figure $4 B$, Table 2). The frequency of $1955 \mathrm{~cm}^{-1}$ suggests that the imidazole becomes trapped in a position in between the $A_{0}$ and $A_{1}$ conformations. It is likely that steric hindrance within the subunit interface prevents the side chain from fully rotating into the $\mathrm{A}_{0}$ conformation. At $\mathrm{pH}$ 3.6, the A substate band of wild-type $\mathrm{HbICO}$ is shifted to $1972 \mathrm{~cm}^{-1}$. This band and its associated photoproduct bands are very broad, indicating an enhanced heterogeneity, likely due to denaturation.

Small, $\mathrm{pH}$-dependent shifts of the optical bands of globins are known to be reliable indicators of distal histidine protonation (76). Therefore, we have investigated the $\mathrm{pH}$ dependence further with UV/visible spectroscopy on aqueous HbICO solutions. We found a cooperative transition, characterized by a pK of $3.7 \pm 0.1$ and a cooperativity parameter $n=4$ (data not shown), which presumably signals denaturation. This interpretation is supported by the presence of a monomeric low-spin hemichrome at acidic $\mathrm{pH}$ in the optical spectra of the oxidized (met) $\mathrm{HbI}$ species $(77,78)$. A simple Henderson-Hasselbalch transition associated with a single-site His-69 protonation as in $\mathrm{MbCO}$ was absent. Therefore, we conclude that, in aqueous solution, the pK of His-69 in HbICO is lower than in MbCO, and it is likely that the His-69 imidazole is more constrained by the subunit interface structure so that the (neutral) distal pocket conformation is energetically preferred. The presence of a significant $1964-\mathrm{cm}^{-1}$ species at room temperature in cryosolvent $(\mathrm{pH} 4)$ may be a sign of weakened subunit interactions that facilitate a conformational change of the His-69 imidazolium moiety.

\section{The Primary Ligand Docking Site B}

We have used two different illumination protocols for photodissociation of our samples, (i) 1$\mathrm{s}$ illumination at $4 \mathrm{~K}$ and (ii) slow cooling from 160 to $4 \mathrm{~K}$ under continuous illumination. For the photoproduct spectra upon 1-s illumination at $4 \mathrm{~K}$, the peak positions and fractional band areas were determined from fits with multiple Gaussians; the best-fit parameters are included in Table 2. From comparison of the photoproduct spectra in the upper and lower right of Figures $4 A$ and $B$, respectively, it is obvious that the two illumination protocols yield very different photoproduct spectra. Based on our prior experience with ligand migration in $\mathrm{Mb}$ and other globins (60,79-81), we anticipate that the CO ligands remain close to the active site upon photolysis at very low temperature, whereas they may become dispersed among a few docking sites within the protein when photolyzed during the slow cooling.

Photolysis of wild-type HbICO by 1-s laser illumination at $4 \mathrm{~K}$ gives rise to a doublet of photoproduct bands at 2114 and $2133 \mathrm{~cm}^{-1}$ (Figure $4 A$ ). The high-frequency band was already noticed in previous work (82). Similar doublets are seen for I25W HbICO and I114F HbICO. In mutant F97Y, the main photoproduct bands are shifted to 2113 and $2135 \mathrm{~cm}^{-1}$. A weak shoulder on the high-frequency side of the $2135-\mathrm{cm}^{-1}$ band can be fitted with an additional 
band at $2141 \mathrm{~cm}^{-1}$. The introduction of a phenylalanine at position B10 in the M37F sample gives rise to a very different photoproduct spectrum, with an apparent triplet of peaks at 2116, 2129 and $2141 \mathrm{~cm}^{-1}$. In wild-type $\mathrm{HbICO}$ at $\mathrm{pH} 4$, and also upon exchange of the distal histidine by an aliphatic residue in H69L HbICO and H69V-I114M HbICO, the splitting of the photoproduct bands is smaller or even absent (Figure 4B). Mutant H69Q HbICO gives again rise to a multitude of overlapping photoproduct bands.

The IR spectrum of $\mathrm{MbCO}$ also displays two photoproduct bands associated with the dominant $\mathrm{A}_{1}$ substate at 2119 and $2131 \mathrm{~cm}^{-1}$. This doublet has been assigned to photolyzed ligands in the primary docking site $\mathrm{B}$ on top of pyrrole $\mathrm{C}$ in two opposing orientations $(70,83,84)$. Comparison of active-site mutants of $\mathrm{MbCO}$ has revealed that the distal histidine is mainly responsible for the splitting (70). Here we propose a similar scenario for wild-type HbICO. Time-resolved x-ray crystallography experiments on M37V HbICO yielded a positive electron density in the distal pocket adjacent to the Val-37 (B10) side chain $5 \mathrm{~ns}$ after photolysis due to photolyzed $\mathrm{CO}$ (85). This position is similar to the photoproduct site B of Mb. In M37V $\mathrm{HbICO}$, the distance between the His-69-N $\varepsilon$ and the ligand is only $3.05 \AA$, whereas the corresponding distance is $3.9 \AA$ in $\mathrm{Mb}$. In agreement with this observation, HbICO features a significantly larger Stark splitting of the B photoproduct doublet (70). This line of evidence is further supported by the photoproduct spectra of H69L and H69V-I114M HbICO, which - in analogy to $\mathrm{H} 64 \mathrm{~L}$ and $\mathrm{H} 64 \mathrm{~V} \mathrm{MbCO}$ - essentially lack the splitting. In mutant M37F, the electric field at the B site is apparently governed by the phenyl side chain located $3 \AA$ away from the $\mathrm{CO}$. As a consequence, the photoproduct spectrum is considerably altered (Figure $4 A$ ) and shows an even further enhanced splitting of the bands (Table 2). This behavior has been observed repeatedly in $\mathrm{Mb}$ upon introduction of aromatic moieties near the photolyzed ligand $(30,58,79)$.

Concerning the assignment of the two $\mathrm{CO}$ orientations to the $\mathrm{B}$ substates, we have proposed that the high-frequency photoproduct species absorbing at $2131 \mathrm{~cm}^{-1}$ in $\mathrm{MbCO}$ points its carbon atom towards the heme iron (70), which was independently supported by combining $\mathrm{MD}$ and QM/MM calculations (84). (Interestingly, Anselmi et al. (86) recently arrived at the opposite assignment based on their computational data for unknown reasons.) The similar primary photoproduct spectrum of $\mathrm{HbICO}$ suggests an identical assignment as for $\mathrm{MbCO}$. An interesting effect can by noticed in Figure $4 A$ when comparing the photoproduct spectra measured after brief and extended illumination. In the latter case, the fractional population in the $2114-\mathrm{cm}^{-1}$ photoproduct state is significantly enhanced in wild-type $\mathrm{HbICO}$, I25W HbICO and especially I114F HbICO. This effect appears to arise from the long exposure to light below $\sim 20 \mathrm{~K}$ because the two $\mathrm{CO}$ orientations are seen to equilibrate at higher temperature (vide infra). Considering that the $\mathrm{HbI}$ distal histidine is closer to the photolyzed ligands ( $3.1 \AA$ (85) versus $3.9 \AA$ (14)), as also inferred from the Stark splitting of the HbI and Mb B bands, one may conjecture that the His-69-NعH - OC orientation is preferentially stabilized due to formation of a weak hydrogen bond.

To probe rebinding from site B, a TDS measurement was started immediately after 1-s illumination of the wild-type $\mathrm{HbICO}$ sample $(\mathrm{pH} 7.2)$ at $4 \mathrm{~K}$. Contour plots of the absorbance changes in the bands of heme-bound and photodissociated $\mathrm{CO}$ are presented in Figure $5 A$ and $\boldsymbol{B}$, respectively. In Figure $5 A$, the dominant population near $1948 \mathrm{~cm}^{-1}$ is seen to rebind between 3 and $130 \mathrm{~K}$; the maximum is located at $45 \mathrm{~K}$, which is also shown in the plot of the absorption change integrated along the wavenumber axis in Figure 6. A pronounced tilt of the contour lines in the TDS map indicates a correlation between the rebinding enthalpy barriers and the $\mathrm{CO}$ stretching frequencies in such a way that a low barrier is associated with a high frequency. This phenomenon is known as kinetic holeburning (KHB); it reveals that a common structural coordinate governs both kinetic and spectroscopic properties (87). The minor substate $(\mathrm{v}=$ $1966 \mathrm{~cm}^{-1}$ ) shows contours up to $40 \mathrm{~K}$ and maximal rebinding at $20 \mathrm{~K}$. 
The photoproduct map also displays KHB and a maximal loss in the photoproduct band at 2133 $\mathrm{cm}^{-1}$ at $45 \mathrm{~K}$ due to rebinding (Figure $5 \mathrm{~B}$ ). The concomitant occurrence of red and black contours at $2114 \mathrm{~cm}^{-1}$ and $2133 \mathrm{~cm}^{-1}$ at $20 \mathrm{~K}$ suggests a redistribution of the $\mathrm{CO}$ ligand between discrete orientations within one docking site (here site B), so that a loss of area in one band is associated with a gain of area in another band at the same temperature. This spectral signature is frequently observed in TDS maps of globins $(28,30,58,88,89)$. The weak contours in the range $80-100 \mathrm{~K}$ are spectrally displaced from the ones at lower temperature, which suggests that they are associated with rebinding from an alternative ligand docking site.

Experimental data as shown in Figure 5 for wild-type $\mathrm{HbICO}$ were collected on all mutant samples and are provided as Supporting Information. Here, we merely present the integrated absorption changes as solid lines in Figure 6, which allow for convenient comparison of ligand rebinding between the different samples. For most samples, the population with the lowest rebinding temperatures (site B) is found to peak in the range $30-50 \mathrm{~K}$. Replacement of His-69 by aliphatic amino acids clearly shifts the rebinding maximum to $<20 \mathrm{~K}$, which indicates that His-69 contributes significantly to the overall rebinding barrier, as is also the case for $\mathrm{MbCO}$ $(23,24,73)$. For $\mathrm{H} 69 \mathrm{Q}$, there is a tail extending up to $75 \mathrm{~K}$ in addition to the peak at $20 \mathrm{~K}$. This observation suggests that the glutamine side chain assumes multiple conformations, as was also observed for the corresponding mutant Mb H64Q (26,90-92). Depending on its particular conformation, Gln-69 may pose more or less steric hindrance to ligand binding.

\section{Secondary Docking Sites}

The photoproduct spectra obtained upon slow-cool illumination most likely yield a mixture of multiple IR spectra from CO ligands in different locations, which cannot be disentangled on the basis of 4-K difference spectra alone. Separation of these components is accomplished by using the TDS method. The contour map of wild-type HbICO after slow-cool illumination (Figure 5C) displays a strongly modified temperature dependence of $\mathrm{CO}$ rebinding in the $\mathrm{A}$ substate at $1948 \mathrm{~cm}^{-1}$. Three discrete populations can be distinguished, peaking at 45,80 and $135 \mathrm{~K}$. They are associated with rebinding from three different photoproduct states, which we shall denote by B, C and D in the order of increasing temperature. A fit of the integrated absorption change (dotted line in Figure 6) with three Gaussian distributions yields the fractional populations of B (60\%), C (37\%) and D (3\%).

The corresponding photoproduct map is plotted in Figure 5D. By calculating difference spectra for two temperatures between which a particular population rebinds, we can isolate the photoproduct spectra associated with this species. The resulting spectra (Figure 7) are associated with $\mathrm{CO}$ ligands trapped in the primary docking site $\mathrm{B}(40 \mathrm{~K}-50 \mathrm{~K})$ and in secondary sites $\mathrm{C}(80 \mathrm{~K}-90 \mathrm{~K})$ and $\mathrm{D}(130 \mathrm{~K}-140 \mathrm{~K})$. In Figure $7 A$, we have also included the difference spectrum calculated from the photoproduct map in Figure $5 B(20 \mathrm{~K}-30 \mathrm{~K})$ to display the second band of the B-site doublet. The contours in Figure $5 D$ indicate that compared with 1-s illumination, the peak at $2114 \mathrm{~cm}^{-1}$ is enhanced; a transfer of photoproduct population from this peak to multiple distinct peaks is observed below $\sim 30 \mathrm{~K}$. In addition to the exchange with the peak at $2133 \mathrm{~cm}^{-1}$ already visible after 1-s illumination (Figure $5 B$ ), population also appears at those wavenumbers where the two bands of photoproduct $C$ are seen to rebind at $80 \mathrm{~K}$, which is the spectral signature for migration of $\mathrm{CO}$ molecules into this site.

The integrated absorption changes (Figure 6, dotted lines) calculated from the slow-cool TDS maps (see Supporting Information) of the mutant samples indicate that the rebinding process at $\sim 80 \mathrm{~K}$ associated with ligands returning from secondary site $\mathrm{C}$ is present in wild-type $\mathrm{HbI}$, H69L, H69Q, M37F and F97Y, but absent in I25W, I114F and H69V-I114M. This result implies that bulky residues introduced at positions 25 and 114 either fill this cavity directly or prohibit access to it. In the X-ray structure of I25W HbICO, the Trp- 25 side chain packs into a cavity which corresponds approximately to the $\mathrm{Mb} \mathrm{Xe} 4$ site (Figure $1 B$ ), formed from the $\mathrm{B}$, 
E, and G helices and lined by Trp-22 (A12), Ile-25 (A15), Ile-118 (G12), Val-121 (G15), Leu-122 (G16) and Trp-135 (H4). Ligand trapping in this site is especially efficient in $\mathrm{HbI}$ mutant M37F (Figure 6) although Phe-37 partially constricts the pathway to the cavity in the A subunit (but not in the B subunit). The same effect has been observed in Mb mutants with aromatic amino acids at position B10, including L29F (93), triple mutant YQR (L29F-H64QT67R) $(58,80)$ and especially L29W, for which the Xe4 cavity is a highly efficient ligand trap at cryogenic temperatures $(18,29)$. The Xe4 site is separated from the distal pocket by a narrow channel bordered by Leu-36 (B9), Leu-73 (E11), and Ile-114 (G8), which in wild-type HbI is relatively free from obstruction. The closest packing distance between the residues at positions G8 and E11 is $5.6 \AA$. However, the channel is largely blocked in mutant I114F, as inferred from the distance of $3.9 \AA$ between the bulky Phe-114 (G8) side chain and Leu-73 (E11) (39). The methionine in mutant H69V-I114M also restricts ligand access to the BEG corner (Figure 2). Based on these findings, the process visible at $\sim 80 \mathrm{~K}$ in the TDS maps is assigned to rebinding from the Xe4 pocket. This conclusion is further supported by molecular dynamics simulations after ligand dissociation in HbI, in which the ligand moves $12 \AA$ away from the heme and docks in a space defined by Ile-114, Pro-117, Ile-118, and Trp-135 (94).

A third, minor fraction of photolyzed ligands rebinds at $\sim 125 \mathrm{~K}$ in wild-type $\mathrm{HbI}$ after extended illumination (Figure $5 \mathrm{C}$ ). A process in the same temperature range is also present in H69L, H69Q, I25W, F97Y, I114F and M37F (Figure 6). In Mb, this process was identified with CO rebinding from the $\mathrm{Xe} 1$ site on the proximal side of the heme. However, there are structural differences between the two proteins that suggest a different assignment for $\mathrm{HbI}$. The $\mathrm{Xe} 1$ site of HbI is bordered by Phe-80 (E18), Phe-111 (G5), Val-142 (H11), the main chain of Phe-97 (F4) and the heme group. The Phe-111 (G5) phenyl ring protrudes into this space and blocks it significantly (48), as evidenced by less than $10 \%$ Xe occupancy in Xe-exposed I25W HbICO crystals (Figure 1). In contrast, the Xe1 site in Mb can be filled with Xe to $97 \%$ under similar conditions (66). However, a bulky indole moiety at position G5 in L104W MbCO completely occludes this cavity (28). Moreover, in HbI, the accessibility of the $\mathrm{HbI} \mathrm{Xe1} \mathrm{site} \mathrm{depends} \mathrm{on}$ the ligation state of the protein. In the R-state, the Phe-97 side chain is located in the subunit interface, whereas it packs in the proximal pocket and also occupies the Xe1 site in the T-state conformation. In mutant M37F, the Xe1 site of subunit B is partially occupied by the Phe-97 side chain even in the ligand-bound state. Therefore, one may expect this photoproduct to be less populated than in wild-type HbI. However, ligand trapping is much more efficient in this mutant (Figure 6). In both I1 14F and H69Q, the Phe-97 side chains remain in the Xe1 pocket also in the CO-bound conformation and should thus completely inhibit any trapping of $\mathrm{CO}$, which is not observed.

Consequently, it appears unlikely that rebinding at $\sim 125 \mathrm{~K}$ is associated with ligands returning from the Xe1 cavity. We instead propose that the secondary docking site $\mathrm{D}$ in $\mathrm{HbI}$ corresponds to the open volume defined by Leu-77 (E15), Trp-135 (H3), Phe-80 (E18), Phe-111 (G5), Leu-138 (H7), Val-139 (H8) and Val-142 (H11), which corresponds to the Xe2 site of Mb. This site can be filled efficiently with xenon atoms (70\% occupancy) in I25W HbICO crystals (Figure $1 B$ ). The occupancy with $\mathrm{CO}$ is smaller, however, due to its different properties and the procedures employed to populate the site, as has been observed earlier for MbCO crystals (95).

\section{The Role of Transient Docking Sites in Physiological Ligand Binding}

Internal cavities of different volume and shape have been identified in a number of heme proteins $(2,66,96,97)$. They are not mere packing defects but play crucial roles in ligand binding in various ways. For example, an exceptionally large internal volume of $\sim 300 \AA^{3}$ exists in neuroglobin, which allows the entire heme prosthetic group to slide deeper into the protein so as to resolve steric conflicts between the exogenous ligand and the distal histidine (97). In the 
mini-hemoglobin of Cerebratulus lacteus, a channel in the protein matrix provides a ligand migration pathway (81). In $\mathrm{Mb}$, the $\mathrm{Xe} 4$ and $\mathrm{Xe} 1$ cavities serve as transient ligand storage sites $(18,20,28,30,69,93,98)$. Covalent bond formation to the heme iron can only occur from the primary docking site, and these additional docking sites lower the rebinding probability until the dissociated ligand can finally leave the protein with the aid of a rare protein fluctuation that opens an escape pathway. Consequently, the efficiency of ligand escape is enhanced by the availability of secondary sites.

To probe the effect of the cavities on physiological ligand binding in HbI, flash photolysis experiments were performed at $20^{\circ} \mathrm{C}$. In all kinetic traces, both microsecond and millisecondto-second kinetic processes are observed (Figure 8). The fast processes produce either a net absorption decrease or increase at the monitoring wavelength of $436 \mathrm{~nm}$ (Figure 8). The decrease is associated with geminate rebinding, i.e., rebinding of $\mathrm{CO}$ molecules that failed to escape from the protein after photodissociation. The absorption increase has recently been shown to be related to a spectral change caused by the R-T transition of the deligated protein (99). It is not present, however, in samples prepared in the glycerol/buffer mixture. There, the geminate process is enhanced.

The slow phase represents bimolecular rebinding from the solvent, as is proven by its $\mathrm{CO}$ concentration dependence. We have fitted this process with an exponential to obtain (i) the (pseudo-first order) apparent rate coefficient, $\lambda_{S}$, for bimolecular CO binding from the solvent and (ii) the amplitude of the solvent process, which allows the fraction of ligands that escape into the solvent after photodissociation, $N_{S}$, to be estimated. The kinetic parameters are compiled in Table 3 . There, the $N_{S}$ values were scaled to the value of 0.95 reported for wildtype HbICO in buffer solution (94). The $\lambda_{S}$ values scatter around the one of wild-type HbICO; the largest increase was observed for H69L ( 100-fold) and the largest decrease for I114F ( 2-fold). For the M37F mutant, it was necessary to use a sum of two exponentials in order to fit the bimolecular phase, with $\lambda_{S}$ values of the two phases differing by a factor of 40 . This observation, which implies that there are two distinct conformations present in the sample that interconvert on time scales slower than the rebinding itself, fits nicely with the presence of two conformations in the x-ray structure of deoxy M37F. For the data taken in buffer, we have converted the $\lambda_{S}$ values to second-order rate coefficients, $k_{\text {on }}$, by using $[\mathrm{CO}]=50 \mu \mathrm{M}$. Also included in Table 3 are the ratios of apparent rate coefficients for the two solvents used.

Ligand escape is highly efficient in wild-type $\mathrm{HbI}$ at physiological temperatures. Blocking access to the Xe4 cavity greatly increases the geminate fractions in I25W and I114F HbICO, and only $\sim 40 \%$ of the ligands escape into the solvent (Figure $8 B$ ). This effect, which has also been observed for $\mathrm{MbCO}$ mutants, highlights the crucial role of protein and ligand dynamics in ligand binding: within a few picoseconds after dissociation, ligands settle in docking site B in the distal heme pocket. This site plays a key role in iron-ligand bond formation because it is engineered such that ligands can reside in B for comparatively long times (i.e., nanoseconds) without rebinding. Ligands may shuttle back and forth between primary docking site B and the secondary sites, which further reduces their probability of rebinding while they are trapped within the protein until large-scale protein fluctuations on nanosecond to microsecond timescales open the channel(s) through which they escape from the protein. Thus, our work on $\mathrm{HbI}$ gives further support of the proposed role of the internal cavities in enhancing ligand escape (29).

\section{The R-T Transition and Ligand Binding}

Conformational motions associated with the R-T transition are known to strongly modulate the ligand binding properties of HbI under physiological conditions $(36,100)$. They involve repositioning of the Phe-97 side chain and the heme plane and, moreover, the interfacial water cluster between the two protomers is also reorganized (40). In the T-state, steric interference 
between the His-69 side chain and the approaching ligand is increased. Consequently, the enthalpy barrier at the binding site is increased (39), which tends to suppress geminate rebinding and to lower the association rate. The latter finding is corroborated by the $\mathrm{CO}$ association kinetics obtained after flash photolysis of HbICO dissolved in buffer and glycerol/ buffer (Figure 8, Table 3). In aqueous solution, wild-type HbICO, the cavity mutants I25W and I114F (and also H69Q to a lesser extent) show a small absorbance increase at $436 \mathrm{~nm}$ after photodissociation on the microsecond time scale, signaling a transition from the high-affinity $\mathrm{R}$-state to the low-affinity T-state. In glycerol/buffer solvent, there is a net decrease due to enhanced geminate rebinding. This process could possibly overcompensate the increase due to the R-T transition. However, bimolecular rebinding is faster in these mutants (Table 3), which suggests that the proteins stay in the more reactive R-state structure in glycerol/buffer. For mutant I114F, a weak decay is visible below $1 \mu$ s in aqueous buffer, but the $\sim 5$-fold higher bimolecular association rate coefficient in glycerol implies that the R-T-type transition is present in buffer but obscured by geminate rebinding (Figure $8 B$ ). These observations suggest that the allosteric transition no longer occurs in the glycerol/buffer solvent. Glycerol raises the osmotic pressure and apparently destabilizes the more hydrated T-state subunit interface relative to the one of the R-state interface (100). The distal mutants H69L and H69V-I114M exhibit a pronounced non-exponential geminate phase (Figure $8 C$ ). They appear to lack the allosteric transition as bimolecular rebinding in glycerol/buffer is slower than in pure buffer. The structure of mutant F97Y remains locked in an R-like conformation even after photolysis, and consequently, its overall association rate is essentially identical in the two solvents (Table 3). In cryosolvent, the geminate yield of F97Y is increased as for all other mutants, because ligand escape is hindered by the effect of solvent viscosity on protein dynamics (12).

Consistent with the conclusions drawn from $\mathrm{CO}$ rebinding, the oxygen equilibrium binding studies reveal that $\mathrm{I} 25 \mathrm{~W}$ and M37F retain highly cooperative oxygen binding, with Hill coefficients of 1.6, while H69Q shows lower levels of cooperativity (Table 4). Compared with the wild-type protein, the oxygen affinities of mutants I25W and M37F are increased $\sim 2$ - and 9 -fold, respectively, whereas the affinity of mutant H69Q is $\sim 7$-fold lower. Rapid autoxidation of the heme iron in H69L and H69V-I1 14M prevented us from making accurate measurements of their oxygen affinities.

\section{Ligand Entry and Exit Routes}

Hard evidence of ligand entry and exit routes in globins has been notoriously difficult to obtain. Early molecular mechanics studies by Case and Karplus (101) suggested that a ligand exit channel can form in Mb by a concerted motion of the side chains of His-64 (E7), Thr-67 (E9) and Val-68 (E10). Moreover, bulky phenyl (102) and isocyanide (33) ligands have been employed as 'molecular doorstops' to induce a conformational change of the distal histidine that opens a ligand entry and exit channel. This so-called histidine gate mechanism has recently been supported by a time-resolved crystallography study on Mb mutant L29W (20). The bulky Trp-29 indole side chain in $\mathrm{L} 29 \mathrm{~W} \mathrm{MbCO}$ acts as an internal gate separating the distal cavity from the Xe4 and Xe1 sites after the CO dissociation $(20,103)$. The extremely long residence time of CO ligands in the $\mathrm{L} 29 \mathrm{~W} \mathrm{Xe} 1$ cavity $\left(t_{1 / 2} \sim 1.5 \mathrm{~ms}\right)$ as compared to wild-type $\mathrm{MbCO}$ $\left(t_{1 / 2} \sim 10 \mu \mathrm{s},(104)\right)$ indicates that alternative exit routes from Xe 1 are by at least two orders of magnitude less efficient than the predominant one in the wild-type protein. Because Trp-29 blocks this key pathway by suppressing ligand migration back to the front distal pocket, this latter volume of the protein must contain the 'main entrance'.

The distal histidine plays a key role in fine-tuning the ligand affinities of globins both sterically and electrostatically. In the $\mathrm{Mb}$ deoxy conformation, the side chain constitutes a direct steric barrier against ligand binding at the heme iron. Once a ligand is bound, it can be stabilized by a hydrogen bond to the imidazole $\mathrm{N} \varepsilon-\mathrm{H}(23,24,105)$. The dual role of this residue in controlling 
both ligand entry/exit and active-site reactivity makes it difficult to disentangle the two functions. Therefore, an apolar substitution at position E7 has multiple effects: (i) it opens a short channel between the heme pocket and the solvent; (ii) it relieves steric hindrance at the binding site and thereby reduces the enthalpy barrier against rebinding at the heme iron, thereby causing an enhanced geminate and faster bimolecular binding; (iii) the $\mathrm{O}_{2}$ affinity is reduced because of the missing additional hydrogen bond. These implications are clearly evident for HbI mutants H69L and H69V-I114M. Bimolecular CO association is very fast as compared to wild-type $\mathrm{HbICO}$ (Table 3), and the fraction of ligands that rebind geminately is significantly enhanced. The latter effect is further amplified by the additional I114M mutation, which reduces the number of available ligand docking sites by narrowing the channel towards the Xe4 cavity. In the H69Q mutant, the changes in the $\mathrm{CO}$ association rate are only minor because the Gln-69 side chain is similar to the His-69 imidazole in size. However, Gln-69 apparently cannot stabilize a bound $\mathrm{O}_{2}$ molecule efficiently, which leads to a 7-fold decrease in the $\mathrm{O}_{2}$ affinity (Table 4). Likewise, Mb mutant H64Q also shows a 7-fold reduced $\mathrm{O}_{2}$ affinity (23).

So how do ligands manage to enter and exit HbI? If ligands were to migrate via the Xe4 site, this route should be completely blocked in mutant $\mathrm{I} 25 \mathrm{~W}$, resulting in a high geminate yield and very slow bimolecular rebinding. Both effects are not observed, however. Another possibility would be a ligand migration pathway involving the Xe 2 site. If this were the case, bimolecular ligand binding in I114F should be remarkably slow, as the channel between the distal pocket and the Xe 2 cavity is severely constricted in this mutant. However, the data in Table 3 refute this hypothesis because the rate coefficient describing bimolecular $\mathrm{CO}$ binding is only slightly lower than its wild-type counterpart. A pathway involving the Xe1 cavity seems particularly unlikely as this site is already partially blocked in $\mathrm{HbI}$ and further occupied by the Phe-97 side chain in the deoxy conformation of the protein. Moreover, mutant M37F showed the most efficient $\mathrm{CO}$ trapping in secondary sites upon extended illumination at low temperatures, but ligand association is slower than in the wild-type protein at ambient temperature, which further supports the notion that the secondary docking sites identified in this work are off-pathway intermediates.

The preceding discussion raises the question as to whether ligands enter and exit also via the distal histidine gate in $\mathrm{HbI}$, as in $\mathrm{Mb}$ and $\mathrm{Hb}$. The fact that the dimer interface of $\mathrm{HbI}$ is formed via the $\mathrm{E}$ and $\mathrm{F}$ helices may give the impression that the ligands are forced to take a different route. On the other hand, the observed reversible incorporation of 6 - 8 water molecules into the dimer interface during the R-T transition indicates a high degree of structural fluidity that may also allow $\mathrm{CO}$ molecules to migrate within the interface. Therefore, it is quite plausible that ligand entry and exit occurs via the histidine gate in $\mathrm{HbI}$.

\section{CONCLUSIONS}

We have explored the rebinding of $\mathrm{CO}$ molecules from different photoproduct states in $\mathrm{HbI}$ using FTIR-TDS at cryogenic temperatures. By studying a set of well-chosen HbI mutants and combining spectroscopy with $\mathrm{x}$-ray structure analysis, three ligand docking sites within the protein matrix were identified, the primary docking site $\mathrm{B}$ in the vicinity of the active site and two secondary sites $\mathrm{C}$ and $\mathrm{D}$, which were assigned to the $\mathrm{Xe} 4$ and $\mathrm{Xe} 2$ cavities. To understand the involvement of these internal sites in physiological ligand binding, the experiments at cryogenic were complemented by flash photolysis experiments on $\mathrm{HbICO}$ and equilibrium binding studies on $\mathrm{HbIO}_{2}$ carried out at ambient temperature. Clear evidence has been provided that the secondary sites are not located on the ligand migration pathway. They rather serve as alternative docking sites so that geminate rebinding, which occurs from site B, is suppressed and, consequently, ligand escape from the protein is highly efficient. The distal histidine, His-69, was shown to play a key role in controlling the enthalpy barrier against covalent bond 
formation with the heme iron and is most likely also involved in opening a channel in the protein matrix for ligand entry and exit.

\section{Supplementary Material}

Refer to Web version on PubMed Central for supplementary material.

\section{Acknowledgements}

Atomic coordinates have been deposited in the Protein Data Bank with the PDB accession codes 2Z85 (deoxy M37F), 2R4W (M37F HbICO), 2R4X (H69V-I114M HbICO), 2R4Y (deoxy H69V-I114M), 2R4Z (I25W HbICO) and 2Z8A (I25W HbICO-Xe).

\section{Abbreviations}

$\mathrm{HbI}$, Scapharca inaequivalvis hemoglobin; HbICO, CO-ligated Scapharca inaequivalvis hemoglobin; Mb, sperm whale myoglobin; FTIR, Fourier transform infrared; TDS, temperature derivative spectroscopy.

\section{REFERENCES}

1. Kapp OH, Moens L, Vanfleteren J, Trotman CN, Suzuki T, Vinogradov SN. Alignment of 700 globin sequences: extent of amino acid substitution and its correlation with variation in volume. Protein Sci 1995;4:2179-2190. [PubMed: 8535255]

2. Pesce A, Nardini M, Dewilde S, Geuens E, Yamauchi K, Ascenzi P, Riggs AF, Moens L, Bolognesi M. The 109 residue nerve tissue minihemoglobin from Cerebratulus lacteus highlights striking structural plasticity of the alpha-helical globin fold. Structure (Camb) 2002;10:725-735. [PubMed: 12015154]

3. Royer WE Jr. Sharma H, Strand K, Knapp JE, Bhyravbhatla B. Lumbricus erythrocruorin at $3.5 \AA$ resolution: architecture of a megadalton respiratory complex. Structure 2006;14:1167-1177. [PubMed: 16843898]

4. Anderson JL, Chapman SK. Ligand probes for heme proteins. Dalton Trans 2005:13-24. [PubMed: 15605142]

5. Chapman, SK.; Daff, S.; Munro, AW. Heme: The most versatile redox centre in biology?. In: Sadler, PJ., editor. Structure and Bonding. Springer-Verlag; Berlin: 1997. p. 39-70.

6. Austin RH, Beeson KW, Eisenstein L, Frauenfelder H, Gunsalus IC. Dynamics of ligand binding to myoglobin. Biochemistry 1975;14:5355-5373. [PubMed: 1191643]

7. Nienhaus GU, Heinzl J, Huenges E, Parak F. Protein Crystal Dynamics Studied by Time-resolved Analysis of X-ray Diffuse Scattering. Nature 1989;338:665-666.

8. Frauenfelder H, Nienhaus GU, Johnson JB. Rate Processes in Proteins. Ber. Bunsenges. Phys. Chem 1991;95:272-278.

9. Ansari A, Jones CM, Henry ER, Hofrichter J, Eaton WA. The role of solvent viscosity in the dynamics of protein conformational changes. Science 1992;256:1796-1798. [PubMed: 1615323]

10. Nienhaus GU, Müller JD, McMahon BH, Frauenfelder H. Exploring the conformational energy landscape of proteins. Physica D 1997;107:297-311.

11. Parak FG, Nienhaus GU. Myoglobin, a paradigm in the study of protein dynamics. ChemPhysChem 2002;3:249-254. [PubMed: 12503170]

12. Fenimore PW, Frauenfelder H, McMahon BH, Parak FG. Slaving: solvent fluctuations dominate protein dynamics and functions. Proc. Natl. Acad. Sci. U S A 2002;99:16047-16051. [PubMed: 12444262]

13. Samuni U, Dantsker D, Roche CJ, Friedman JM. Ligand recombination and a hierarchy of solvent slaved dynamics: the origin of kinetic phases in hemeproteins. Gene 2007;398:234-248. [PubMed: 17570619] 
14. Schlichting I, Berendzen J, Phillips GN Jr. Sweet RM. Crystal structure of photolysed carbonmonoxymyoglobin. Nature 1994;371:808-812. [PubMed: 7935843]

15. Teng TY, Srajer V, Moffat K. Photolysis-induced structural changes in single crystals of carbonmonoxy myoglobin at 40 K. Nat. Struct. Biol 1994;1:701-705. [PubMed: 7634074]

16. Hartmann H, Zinser S, Komninos P, Schneider RT, Nienhaus GU, Parak F. X-ray structure determination of a metastable state of carbonmonoxy myoglobin after photodissociation. Proc. Natl. Acad. Sci. U S A 1996;93:7013-7016. [PubMed: 8692935]

17. Brunori M, Vallone B, Cutruzzola F, Travaglini-Allocatelli C, Berendzen J, Chu K, Sweet RM, Schlichting I. The role of cavities in protein dynamics: crystal structure of a photolytic intermediate of a mutant myoglobin. Proc. Natl. Acad. Sci. U S A 2000;97:2058-2063. [PubMed: 10681426]

18. Ostermann A, Waschipky R, Parak FG, Nienhaus GU. Ligand binding and conformational motions in myoglobin. Nature 2000;404:205-208. [PubMed: 10724176]

19. Chu K, Vojtechovsky J, McMahon BH, Sweet RM, Berendzen J, Schlichting I. Structure of a ligandbinding intermediate in wild-type carbonmonoxy myoglobin. Nature 2000;403:921-923. [PubMed: 10706294]

20. Schmidt M, Nienhaus K, Pahl R, Krasselt A, Anderson S, Parak F, Nienhaus GU, Srajer V. Ligand migration pathway and protein dynamics in myoglobin: a time-resolved crystallographic study on L29W MbCO. Proc. Natl. Acad. Sci. U S A 2005;102:11704-11709. [PubMed: 16085709]

21. Alben JO, Beece D, Bowne SF, Doster W, Eisenstein L, Frauenfelder H, Good D, McDonald JD, Marden MC, Moh PP, Reinisch L, Reynolds AH, Shyamsunder E, Yue KT. Infrared spectroscopy of photodissociated carboxymyoglobin at low temperatures. Proc. Natl. Acad. Sci. U S A 1982;79:3744-3748. [PubMed: 6954517]

22. Henry ER, Sommer JH, Hofrichter J, Eaton WA. Geminate recombination of carbon monoxide to myoglobin. J. Mol. Biol 1983;166:443-451. [PubMed: 6854651]

23. Rohlfs RJ, Mathews AJ, Carver TE, Olson JS, Springer BA, Egeberg KD, Sligar SG. The effects of amino acid substitution at position E7 (residue 64) on the kinetics of ligand binding to sperm whale myoglobin. J. Biol. Chem 1990;265:3168-3176. [PubMed: 2303446]

24. Carver TE, Rohlfs RJ, Olson JS, Gibson QH, Blackmore RS, Springer BA, Sligar SG. Analysis of the kinetic barriers for ligand binding to sperm whale myoglobin using site-directed mutagenesis and laser photolysis techniques. J. Biol. Chem 1990;265:20007-20020. [PubMed: 2246277]

25. Steinbach PJ, Ansari A, Berendzen J, Braunstein D, Chu K, Cowen BR, Ehrenstein D, Frauenfelder H, Johnson JB, Lamb DC, Luck S, Mourant JR, Nienhaus GU, Ormos P, Philipp R, Xie A, Young $\mathrm{RD}$. Ligand binding to heme proteins: connection between dynamics and function. Biochemistry 1991;30:3988-4001. [PubMed: 2018767]

26. Balasubramanian S, Lambright DG, Boxer SG. Perturbations of the distal heme pocket in human myoglobin mutants probed by infrared spectroscopy of bound $\mathrm{CO}$ : correlation with ligand binding kinetics. Proc. Natl. Acad. Sci. U S A 1993;90:4718-4722. [PubMed: 8506324]

27. Nienhaus GU, Nienhaus K. Infrared Study of Carbon Monoxide Migration among Internal Cavities of Myoglobin Mutant L29W. J. Biol. Phys 2002;28:163-172.

28. Nienhaus K, Deng P, Kriegl JM, Nienhaus GU. Structural Dynamics of Myoglobin: The Effect of Internal Cavities on Ligand Migration and Binding. Biochemistry 2003;42:9647-9658. [PubMed: 12911306]

29. Nienhaus K, Deng P, Kriegl JM, Nienhaus GU. Structural Dynamics of Myoglobin: Spectroscopic and Structural Characterization of Ligand Docking Sites in Myoglobin Mutant L29W. Biochemistry 2003;42:9633-9646. [PubMed: 12911305]

30. Nienhaus K, Deng P, Olson JS, Warren JJ, Nienhaus GU. Structural Dynamics of Myoglobin: Ligand Migration and Binding in Valine 68 Mutants. J. Biol. Chem 2003;278:42532-42544. [PubMed: 12907676]

31. Kriegl JM, Nienhaus K, Deng P, Fuchs J, Nienhaus GU. Ligand dynamics in a protein internal cavity. Proc. Natl. Acad. Sci. U S A 2003;100:7069-7074. [PubMed: 12773621]

32. Perutz MF. Myoglobin and haemoglobin: role of distal residues in reactions with haem ligands. Trends Biochem. Sci 1989;14:42-44. [PubMed: 2650040]

33. Johnson KA, Olson JS, Phillips GN Jr. Structure of myoglobin-ethyl isocyanide. Histidine as a swinging door for ligand entry. J. Mol. Biol 1989;207:459-463. [PubMed: 2754735] 
34. Antonini E, Brunori M. Hemoglobin. Annu. Rev. Biochem 1970;39:977-1042. [PubMed: 4320264]

35. Eaton WA, Henry ER, Hofrichter J, Mozzarelli A. Is cooperative oxygen binding by hemoglobin really understood? Nat. Struct. Biol 1999;6:351-358. [PubMed: 10201404]

36. Knapp JE, Bonham MA, Gibson QH, Nichols JC, Royer WE Jr. Residue F4 plays a key role in modulating oxygen affinity and cooperativity in Scapharca dimeric hemoglobin. Biochemistry 2005;44:14419-14430. [PubMed: 16262242]

37. Zhou Y, Zhou H, Karplus M. Cooperativity in Scapharca dimeric hemoglobin: simulation of binding intermediates and elucidation of the role of interfacial water. J. Mol. Biol 2003;326:593-606. [PubMed: 12559925]

38. Ceci P, Giangiacomo L, Boffi A, Chiancone E. The mutation K30D disrupts the only salt bridge at the subunit interface of the homodimeric hemoglobin from Scapharca inaequivalvis and changes the mechanism of cooperativity. J. Biol. Chem 2002;277:6929-6933. [PubMed: 11741990]

39. Knapp JE, Gibson QH, Cushing L, Royer WE Jr. Restricting the ligand-linked heme movement in Scapharca dimeric hemoglobin reveals tight coupling between distal and proximal contributions to cooperativity. Biochemistry 2001;40:14795-14805. [PubMed: 11732898]

40. Pardanani A, Gambacurta A, Ascoli F, Royer WE Jr. Mutational destabilization of the critical interface water cluster in Scapharca dimeric hemoglobin: structural basis for altered allosteric activity. J. Mol. Biol 1998;284:729-739. [PubMed: 9826511]

41. Zamparelli C, Verzili D, Boffi A, Chiancone E, Takahashi S, Rousseau DL, Regan R, Gibson QH. The unique heme-heme interactions of the homodimeric Scapharca inaequivalvis hemoglobin as probed in the protein reconstituted with unnatural 2,4 heme derivatives. Arch. Biochem. Biophys 1997;339:275-282. [PubMed: 9056259]

42. Royer WE Jr. Fox RA, Smith FR, Zhu D, Braswell EH. Ligand linked assembly of Scapharca dimeric hemoglobin. J. Biol. Chem 1997;272:5689-5694. [PubMed: 9038179]

43. Mozzarelli A, Bettati S, Rivetti C, Rossi GL, Colotti G, Chiancone E. Cooperative oxygen binding to Scapharca inaequivalvis hemoglobin in the crystal. J. Biol. Chem 1996;271:3627-3632. [PubMed: 8631972]

44. Chiancone E, Verzili D, Boffi A, Royer WE Jr. Hendrickson WA. A cooperative hemoglobin with directly communicating hemes. The Scapharca inaequivalvis homodimer. Biophys. Chem 1990;37:287-292. [PubMed: 2285790]

45. Chiancone E, Gibson QH. Ligand binding to the dimeric hemoglobin from Scapharca inaequivalvis, a hemoglobin with a novel mechanism for cooperativity. J. Biol. Chem 1989;264:21062-21065. [PubMed: 2592367]

46. Antonini E, Ascoli F, Brunori M, Chiancone E, Verzili D, Morris RJ, Gibson QH. Kinetics of ligand binding and quaternary conformational change in the homodimeric hemoglobin from Scapharca inaequivalvis. J. Biol. Chem 1984;259:6730-6738. [PubMed: 6725269]

47. Perutz MF. Stereochemistry of cooperative effects in haemoglobin. Nature 1970;228:726-739. [PubMed: 5528785]

48. Royer WE Jr. High-resolution crystallographic analysis of a co-operative dimeric hemoglobin. J. Mol. Biol 1994;235:657-681. [PubMed: 8289287]

49. Royer WE Jr. Knapp JE, Strand K, Heaslet HA. Cooperative hemoglobins: conserved fold, diverse quaternary assemblies and allosteric mechanisms. Trends Biochem. Sci 2001;26:297-304. [PubMed: 11343922]

50. Summerford CM, Pardanani A, Betts AH, Poteete AR, Colotti G, Royer WE Jr. Bacterial expression of Scapharca dimeric hemoglobin: a simple model system for investigating protein cooperatively. Protein Eng 1995;8:593-599. [PubMed: 8532684]

51. Otwinowski Z, Minor W. Processing X-ray diffraction data collected in oscillation mode. Methods Enzymol 1997;276:307-326.

52. Bailey S. The CCP4 suite: programs for protein crystallography. Acta Cryst. D 1994;50:760-763. [PubMed: 15299374]

53. Bruenger AT, Adams PD, Clore GM, DeLano WL, Gros P, Grosse-Kunstleve RW, Jiang JS, Kuszewski J, Nilges M, Pannu NS, Read RJ, Rice LM, Simonson T, Warren GL. Crystallography \& NMR system: A new software suite for macromolecular structure determination. Acta Cryst. D 1998;54:905-921. [PubMed: 9757107] 
54. Jones TA, Zou JY, Cowan SW, Kjeldgaard. Improved methods for building protein models in electron density maps and the location of errors in these models. Acta Cryst. A 1991;47:110-119. [PubMed: 2025413]

55. Sheldrick GM. Phase annealing in SHELX-90: direct methods for larger structures. Acta Cryst. A 1990;46:467-473.

56. Esnouf RM. Further additions to MolScript version 1.4, including reading and contouring of electrondensity maps. Acta Cryst. D 1999;55:938-940. [PubMed: 10089341]

57. Merritt EA, Bacon DJ. Raster3D: Photorealistic molecular graphics. Methods Enzymol 1997;277:505-524. [PubMed: 18488322]

58. Lamb DC, Nienhaus K, Arcovito A, Draghi F, Miele AE, Brunori M, Nienhaus GU. Structural dynamics of myoglobin: ligand migration among protein cavities studied by Fourier transform infrared/temperature derivative spectroscopy. J. Biol. Chem 2002;277:11636-11644. [PubMed: 11792698]

59. Berendzen J, Braunstein D. Temperature-derivative spectroscopy: a tool for protein dynamics. Proc. Natl. Acad. Sci. U S A 1990;87:1-5. [PubMed: 2296572]

60. Nienhaus GU, Mourant JR, Chu K, Frauenfelder H. Ligand binding to heme proteins: the effect of light on ligand binding in myoglobin. Biochemistry 1994;33:13413-13430. [PubMed: 7947750]

61. Chu K, Ernst RM, Frauenfelder H, Mourant JR, Nienhaus GU, Philipp R. Light-induced and thermal relaxation in a protein. Phys. Rev. Lett 1995;74:2607-2610. [PubMed: 10057970]

62. Ehrenstein D, Nienhaus GU. Conformational substates in azurin. Proc. Natl. Acad. Sci. U S A 1992;89:9681-9685. [PubMed: 1409682]

63. Lehle H, Kriegl JM, Nienhaus K, Deng P, Fengler S, Nienhaus GU. Probing electric fields in protein cavities by using the vibrational Stark effect of carbon monoxide. Biophys. J 2005;88:1978-1990. [PubMed: 15596507]

64. Nienhaus K, Maes EM, Weichsel A, Montfort WR, Nienhaus GU. Structural dynamics controls nitric oxide affinity in nitrophorin 4. J. Biol. Chem 2004;279:39401-39407. [PubMed: 15258143]

65. Ansari A, Jones CM, Henry ER, Hofrichter J, Eaton WA. Photoselection in polarized photolysis experiments on heme proteins. Biophys. J 1993;64:852-868. [PubMed: 8471730]

66. Tilton RF Jr. Kuntz ID Jr. Petsko GA. Cavities in proteins: structure of a metmyoglobin-xenon complex solved to 1.9 Å. Biochemistry 1984;23:2849-2857. [PubMed: 6466620]

67. Yang F, Phillips GN Jr. Crystal structures of CO-, deoxy- and met-myoglobins at various pH values. J. Mol. Biol 1996;256:762-774. [PubMed: 8642596]

68. Müller JD, McMahon BH, Chien EY, Sligar SG, Nienhaus GU. Connection between the taxonomic substates and protonation of histidines 64 and 97 in carbonmonoxy myoglobin. Biophys. J 1999;77:1036-1051. [PubMed: 10423448]

69. Bourgeois D, Vallone B, Schotte F, Arcovito A, Miele AE, Sciara G, Wulff M, Anfinrud P, Brunori M. Complex landscape of protein structural dynamics unveiled by nanosecond Laue crystallography. Proc. Natl. Acad. Sci. U S A 2003;100:8704-8709. [PubMed: 12847289]

70. Nienhaus K, Olson JS, Franzen S, Nienhaus GU. The origin of Stark splitting in the initial photoproduct state of MbCO. J. Am. Chem. Soc 2005;127:40-41. [PubMed: 15631438]

71. Park ES, Boxer SG. Origins of the sensitivity of molecular vibrations on electric fields: Carbonyl and Nitrosyl Stretches in Model Compounds and Proteins. J. Phys. Chem 2002;106:5800-5806.

72. Weber RE, Vinogradov SN. Nonvertebrate hemoglobins: functions and molecular adaptations. Physiol. Rev 2001;81:569-628. [PubMed: 11274340]

73. Braunstein DP, Chu K, Egeberg KD, Frauenfelder H, Mourant JR, Nienhaus GU, Ormos P, Sligar SG, Springer BA, Young RD. Ligand binding to heme proteins: III. FTIR studies of His-E7 and ValE11 mutants of carbonmonoxymyoglobin. Biophys. J 1993;65:2447-2454. [PubMed: 8312483]

74. Li T, Quillin ML, Phillips GN Jr. Olson JS. Structural determinants of the stretching frequency of CO bound to myoglobin. Biochemistry 1994;33:1433-1446. [PubMed: 8312263]

75. Vojtechovsky J, Chu K, Berendzen J, Sweet RM, Schlichting I. Crystal structures of myoglobinligand complexes at near-atomic resolution. Biophys. J 1999;77:2153-2174. [PubMed: 10512835]

76. Nienhaus K, Kriegl JM, Nienhaus GU. Structural dynamics in the active site of murine neuroglobin and its effects on ligand binding. J. Biol. Chem 2004;279:22944-22952. [PubMed: 15016813] 
77. Spagnuolo C, Ascoli F, Chiancone E, Vecchini P, Antonini E. Dimeric and tetrameric hemoglobins from the mollusc Scapharca inaequivalvis. The oxidation reaction. J. Mol. Biol 1983;164:627-644. [PubMed: 6842601]

78. Boffi A, Guarrera L, Giangiacomo L, Spagnuolo C, Chiancone E. Proximal and distal effects on the coordination chemistry of ferric Scapharca homodimeric hemoglobin as revealed by heme pocket mutants. Biochemistry 2000;39:3500-3504. [PubMed: 10727246]

79. Nienhaus K, Lamb DC, Deng P, Nienhaus GU. The effect of ligand dynamics on heme electronic transition band III in myoglobin. Biophys. J 2002;82:1059-1067. [PubMed: 11806945]

80. Lamb DC, Arcovito A, Nienhaus K, Minkow O, Draghi F, Brunori M, Nienhaus GU. Structural dynamics of myoglobin: an infrared kinetic study of ligand migration in mutants YQR and YQRF. Biophys. Chem 2004;109:41-58. [PubMed: 15059658]

81. Deng P, Nienhaus K, Palladino P, Olson JS, Blouin G, Moens L, Dewilde S, Geuens E, Nienhaus GU. Transient ligand docking sites in Cerebratulus lacteus mini-hemoglobin. Gene. 2007published online before print

82. Song S, Boffi A, Chiancone E, Rousseau DL. Protein-heme interactions in hemoglobin from the mollusc Scapharca inaequivalvis: evidence from resonance Raman scattering. Biochemistry 1993;32:6330-6336. [PubMed: 8518278]

83. Lim M, Jackson TA, Anfinrud PA. Ultrafast rotation and trapping of carbon monoxide dissociated from myoglobin. Nat. Struct. Biol 1997;4:209-214. [PubMed: 9164462]

84. Meuwly M. On the influence of the local environment on the CO stretching frequencies in native myoglobin: assignment of the B-states in MbCO. Chemphyschem 2006;7:2061-2063. [PubMed: 16955519]

85. Knapp JE, Pahl R, Srajer V, Royer WE Jr. Allosteric action in real time: time-resolved crystallographic studies of a cooperative dimeric hemoglobin. Proc. Natl. Acad. Sci. U S A 2006;103:7649-7654. [PubMed: 16684887]

86. Anselmi M, Aschi M, Di Nola A, Amadei A. Theoretical characterization of carbon monoxide vibrational spectrum in sperm whale myoglobin distal pocket. Biophys. J 2007;92:3442-3447. [PubMed: 17307822]

87. Ormos P, Szaraz S, Cupane A, Nienhaus GU. Structural factors controlling ligand binding to myoglobin: a kinetic hole-burning study. Proc. Natl. Acad. Sci. U S A 1998;95:6762-6767. [PubMed: 9618486]

88. Mourant JR, Braunstein DP, Chu K, Frauenfelder H, Nienhaus GU, Ormos P, Young RD. Ligand binding to heme proteins: II. Transitions in the heme pocket of myoglobin. Biophys. J 1993;65:14961507. [PubMed: 8274643]

89. Bredenbeck J, Helbing J, Nienhaus K, Nienhaus GU, Hamm P. Protein ligand migration mapped by nonequilibrium 2D-IR exchange spectroscopy. Proc. Natl. Acad. Sci. U S A 2007;104:14243-14248. [PubMed: 17261808]

90. Tada T, Watanabe YH, Matsuoka A, Ikeda-Saito M, Imai K, Ni-hei Y, Shikama K. African elephant myoglobin with an unusual autoxidation behavior: comparison with the H64Q mutant of sperm whale myoglobin. Biochim. Biophys. Acta 1998;1387:165-176. [PubMed: 9748556]

91. Quillin ML, Arduini RM, Olson JS, Phillips GN Jr. High-resolution crystal structures of distal histidine mutants of sperm whale myoglobin. J. Mol. Biol 1993;234:140-155. [PubMed: 8230194]

92. Zhao X, Vyas K, Nguyen BD, Rajarathnam K, La Mar GN, Li T, Phillips GN Jr. Eich RF, Olson JS, Ling J, et al. A double mutant of sperm whale myoglobin mimics the structure and function of elephant myoglobin. J. Biol. Chem 1995;270:20763-20774. [PubMed: 7657659]

93. Schotte F, Lim M, Jackson TA, Smirnov AV, Soman J, Olson JS, Phillips GN Jr. Wulff M, Anfinrud PA. Watching a protein as it functions with 150-ps time-resolved x-ray crystallography. Science 2003;300:1944-1947. [PubMed: 12817148]

94. Chiancone E, Elber R, Royer WE Jr. Regan R, Gibson QH. Ligand binding and conformation change in the dimeric hemoglobin of the clam Scapharca inaequivalvis. J. Biol. Chem 1993;268:5711-5718. [PubMed: 8449933]

95. Nienhaus GU, Chu K, Jesse K. Structural heterogeneity and ligand binding in carbonmonoxy myoglobin crystals at cryogenic temperatures. Biochemistry 1998;37:6819-6823. [PubMed: 9578567] 
96. Vallone B, Nienhaus K, Brunori M, Nienhaus GU. The structure of murine neuroglobin: novel pathways for ligand migration and binding. Proteins 2004;56:85-92. [PubMed: 15162488]

97. Vallone B, Nienhaus K, Matthes A, Brunori M, Nienhaus GU. The structure of carbonmonoxy neuroglobin reveals a heme-sliding mechanism for control of ligand affinity. Proc. Natl. Acad. Sci. U S A 2004;101:17351-17356. [PubMed: 15548613]

98. Scott EE, Gibson QH, Olson JS. Mapping the pathways for $\mathrm{O}_{2}$ entry into and exit from myoglobin. J. Biol. Chem 2001;276:5177-5188. [PubMed: 11018046]

99. Nichols JC, Royer WE Jr. Gibson QH. An optical signal correlated with the allosteric transition in Scapharca inaequivalvis HbI. Biochemistry 2006;45:15748-15755. [PubMed: 17176097]

100. Royer WE Jr. Pardanani A, Gibson QH, Peterson ES, Friedman JM. Ordered water molecules as key allosteric mediators in a cooperative dimeric hemoglobin. Proc. Natl. Acad. Sci. U S A 1996;93:14526-14531. [PubMed: 8962085]

101. Case DA, Karplus M. Dynamics of ligand binding to heme proteins. J. Mol. Biol 1979;132:343368. [PubMed: 533895]

102. Ringe D, Petsko GA, Kerr DE, Ortiz de Montellano PR. Reaction of myoglobin with phenylhydrazine: a molecular doorstop. Biochemistry 1984;23:2-4. [PubMed: 6691963]

103. Nienhaus K, Ostermann A, Nienhaus GU, Parak FG, Schmidt M. Ligand migration and protein fluctuations in myoglobin mutant L29W. Biochemistry 2005;44:5095-5105. [PubMed: 15794647]

104. Srajer V, Ren Z, Teng TY, Schmidt M, Ursby T, Bourgeois D, Pradervand C, Schildkamp W, Wulff M, Moffat K. Protein conformational relaxation and ligand migration in myoglobin: a nanosecond to millisecond molecular movie from time-resolved Laue X-ray diffraction. Biochemistry 2001;40:13802-13815. [PubMed: 11705369]

105. Springer BA, Egeberg KD, Sligar SG, Rohlfs RJ, Mathews AJ, Olson JS. Discrimination between oxygen and carbon monoxide and inhibition of autooxidation by myoglobin. Site-directed mutagenesis of the distal histidine. J. Biol. Chem 1989;264:3057-3060. [PubMed: 2644279] 

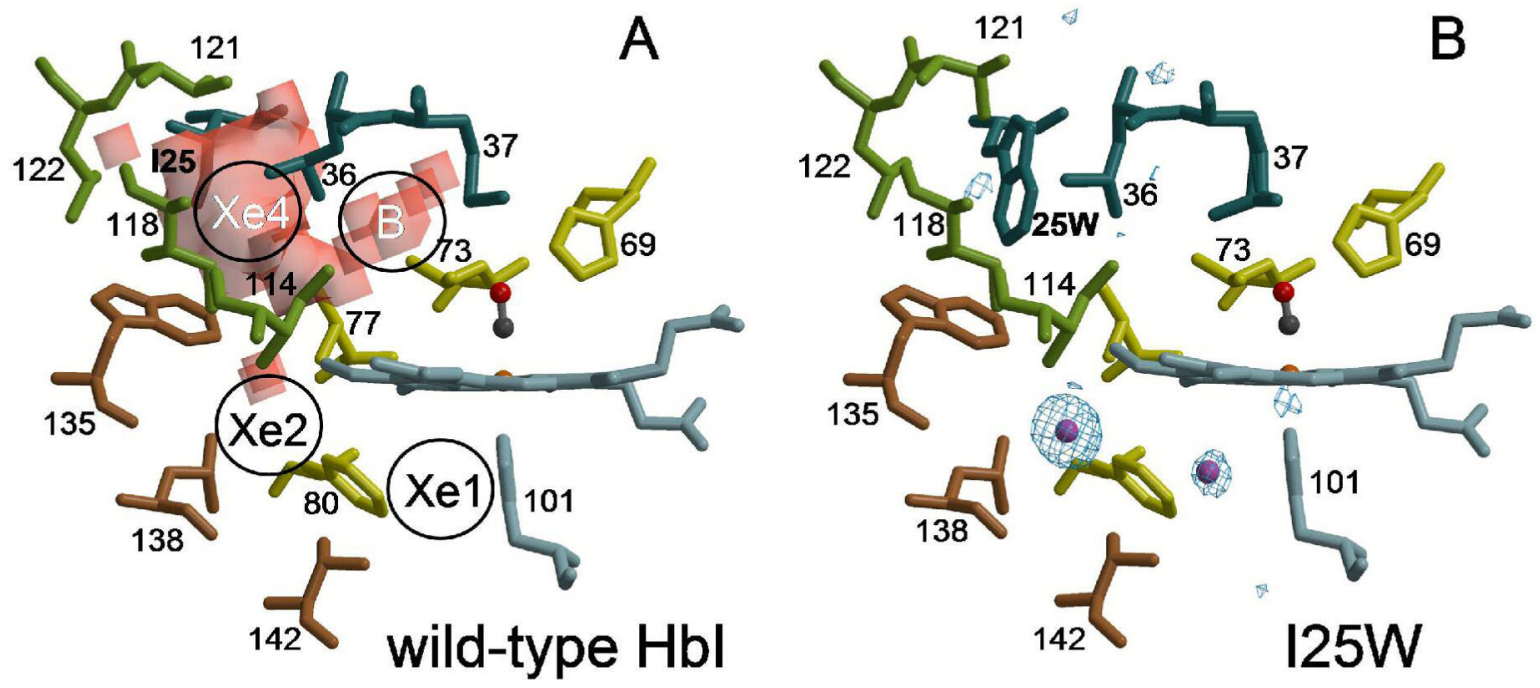

FIGURE 1.

Structural models of wild-type and mutant I25W HbICO. Residues from the B, E, G, and H helices are numbered according to their primary sequence position and are depicted in blue, gold, green and brown, respectively. (A) Semi-transparent surfaces represent internal cavities; the locations of the B, Xe1, Xe2 and Xe4 sites are also labeled. (B) The model of I25W HbICO derivatized with $\mathrm{Xe}$ is superimposed on a Fo $25 \mathrm{~W}-\mathrm{Xe}^{-\mathrm{FO}_{\mathrm{I}} 5 \mathrm{~W}}$ difference map. Xe atoms occupy the $\mathrm{Xe} 1$ and $\mathrm{Xe} 2$ sites but not Xe4 because it is already filled by Trp- 25 . 

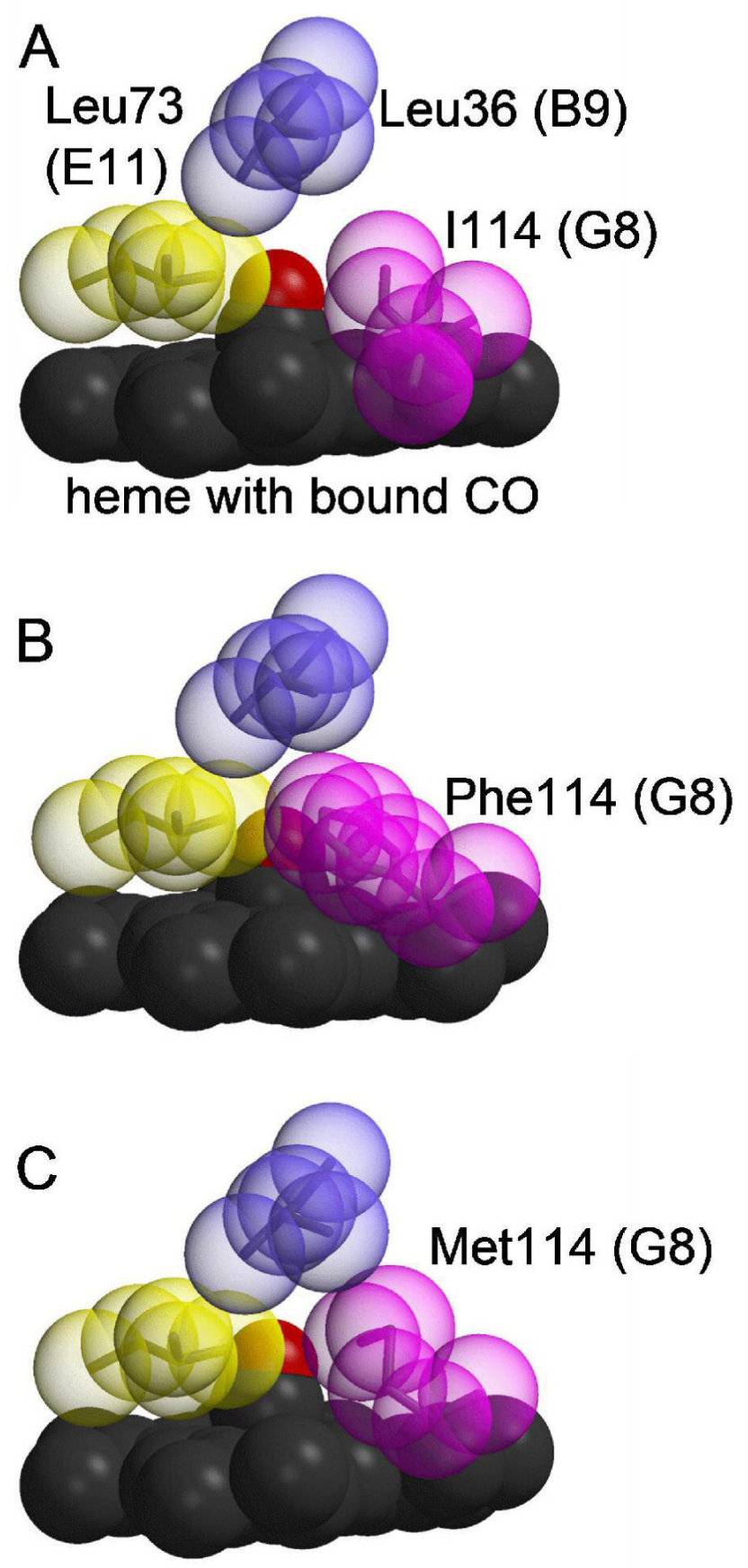

FIGURE 2.

Side chain packing at the active sites of wild-type and mutant HbICO. The bottleneck between the distal pocket and the Xe4 cavity is formed by the side chains of residues B9 (blue), E11 (yellow), and G8 (magenta), represented by van der Waals spheres. This narrow channel is open in (A) wild-type HbI but severely obstructed when either a (B) phenylalanine or (C) methionine is introduced at position $114(\mathrm{G} 8)$. 

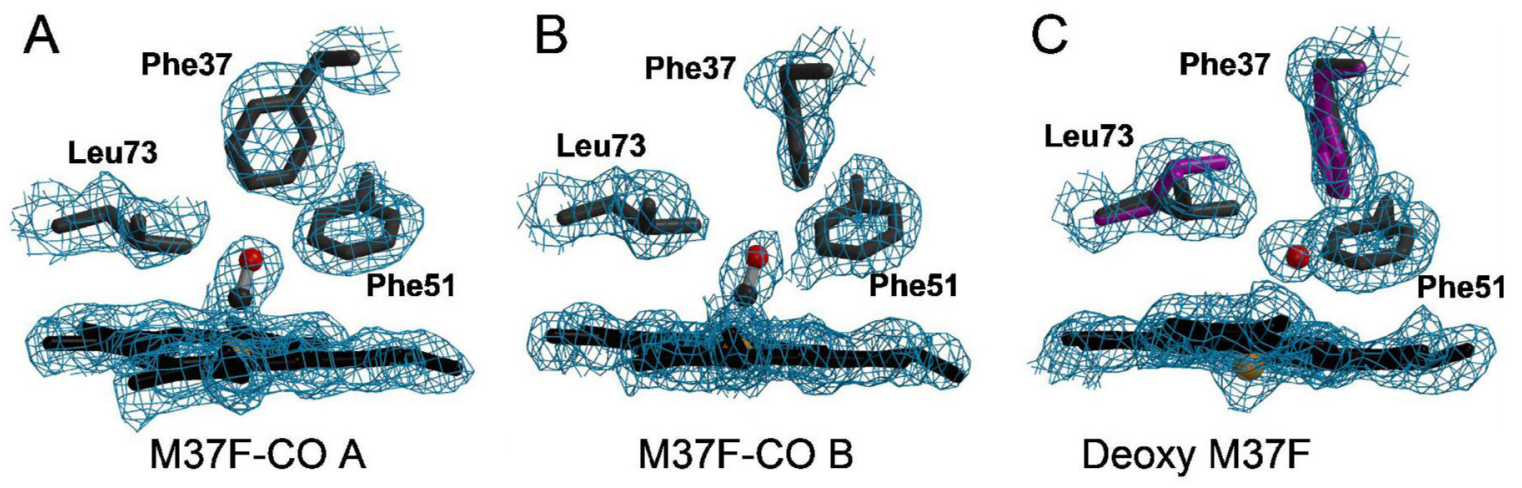

FIGURE 3.

Atomic models of M37F HbI superimposed on $2 \mathrm{Fo}-\mathrm{Fc}$ simulated annealing omit maps in which the Phe-37 side chain is omitted from the map calculations. In the CO-ligated species, Phe-37 is positioned (A) near Leu-73 in the A subunit and (B) near Phe-51 in the B subunit. (C) In deoxy M37F, Leu-73 and Phe-37 occupy both a major (black) and a minor (magenta) conformation in both subunits. The minor Phe- 37 conformation positions the side chain within the ligand binding site. In the major conformation, the side chain points away from binding site, towards the back. 


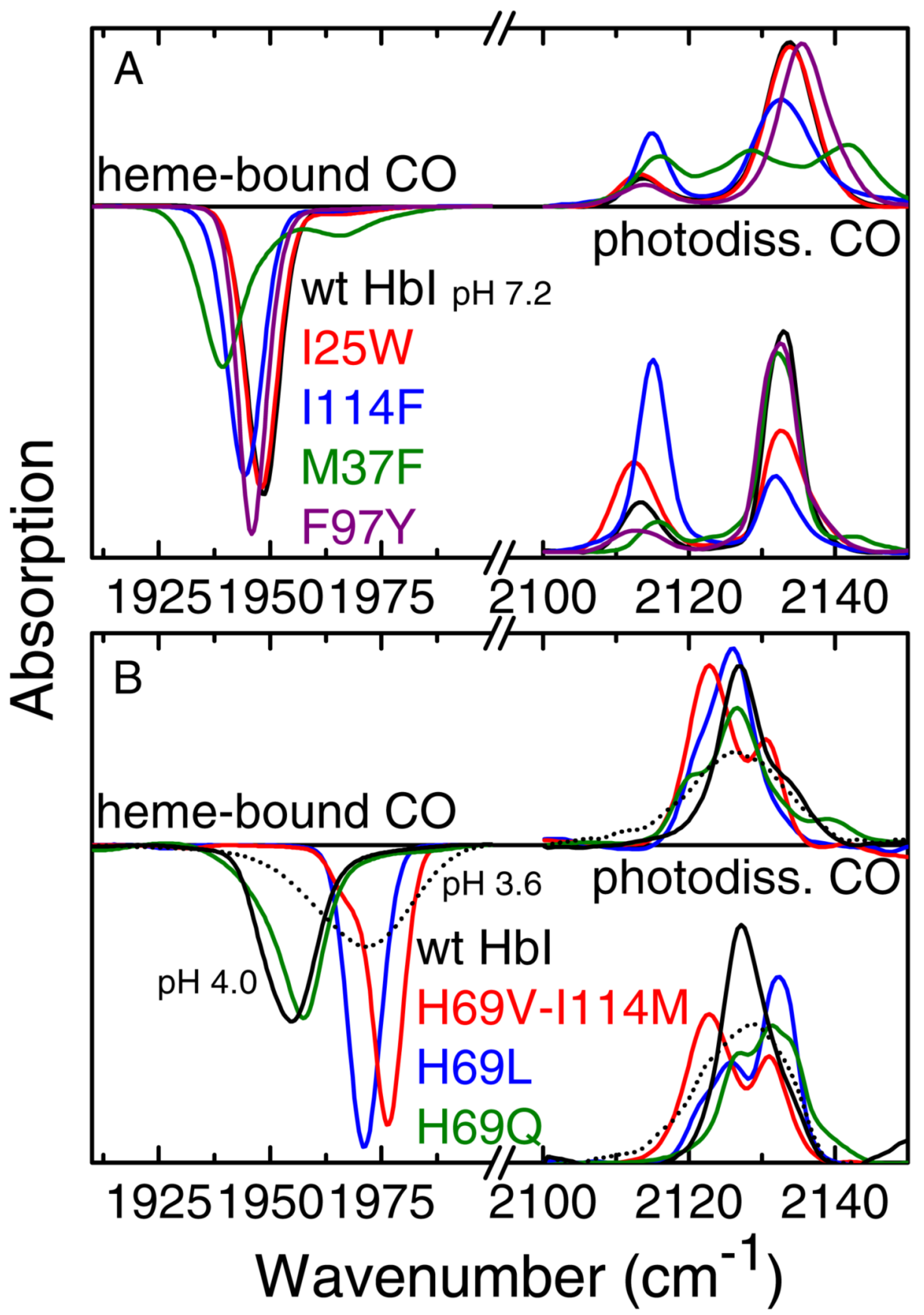

FIGURE 4.

FTIR photolysis difference spectra of $\mathrm{HbICO}$ samples at $4 \mathrm{~K}$. Spectra of heme-bound $\mathrm{CO}$ are plotted on the left, spectra of photodissociated $\mathrm{CO}$ obtained after 1-s illumination at $4 \mathrm{~K}$ are plotted in the top right, and those obtained after slow cooling from 160 to $4 \mathrm{~K}$ under continuous illumination are plotted in the lower right in each panel. (A) wild-type HbI, pH 7.2 (black), I25W (red), M37F (green), I114F (blue) and F97Y (violet). (B) wild-type HbI, pH 4.0 (black), wild-type HbI, pH 3.6 (black, dotted), H69L (blue), H69Q (green) and H69V-I114M (red). 

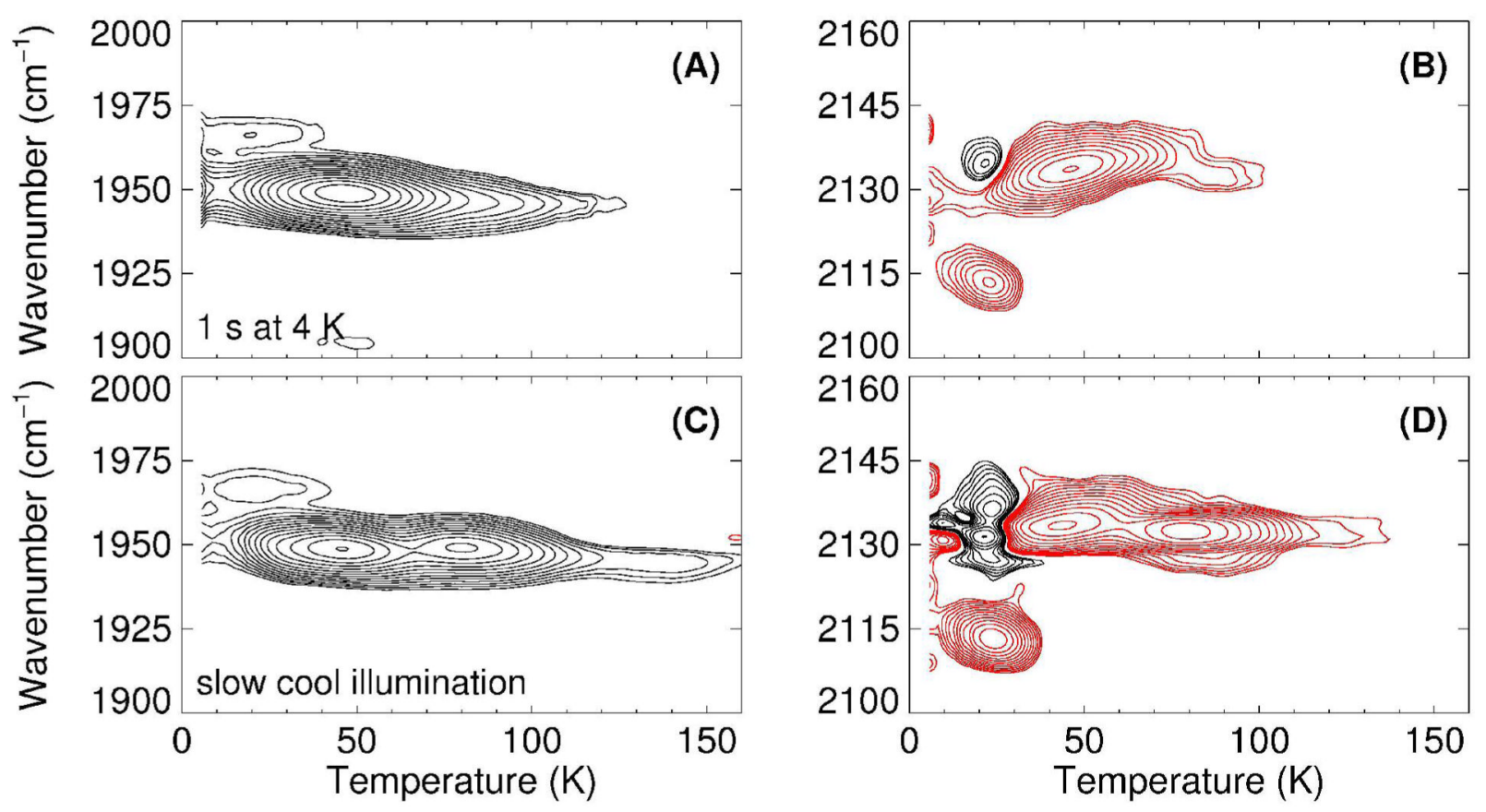

FIGURE 5.

TDS contour maps of wild-type HbICO. Data were taken (A, B) after 1-s illumination at $4 \mathrm{~K}$ and (C, D) after slow-cooling from 160 to $4 \mathrm{~K}$ under continuous illumination. (A, C) Absorption changes in the bands of heme-bound CO. (B, D) Absorption changes in the photoproduct bands. Contours are spaced logarithmically, black and red lines represent increasing and decreasing absorption, respectively. 


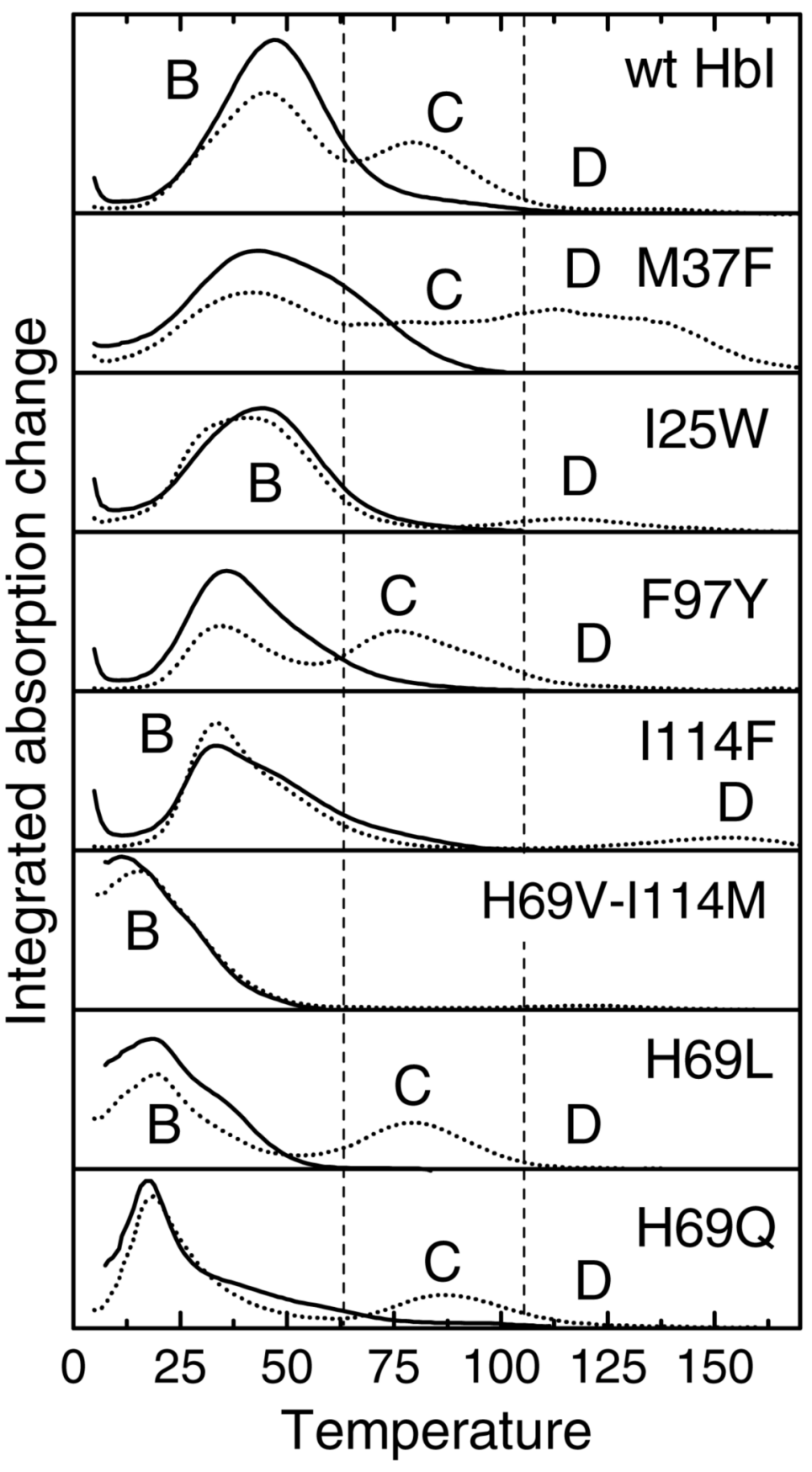

FIGURE 6.

Temperature dependence of integrated absorption changes calculated from TDS data of wildtype $\mathrm{HbICO}$ and mutant HbICO samples. The data were integrated over the entire spectral region of the A substate bands; solid lines: 1-s illumination at $4 \mathrm{~K}$; dotted lines: extended illumination during slow cooling $(5 \mathrm{mK} / \mathrm{s})$ from 160 to $4 \mathrm{~K}$. 


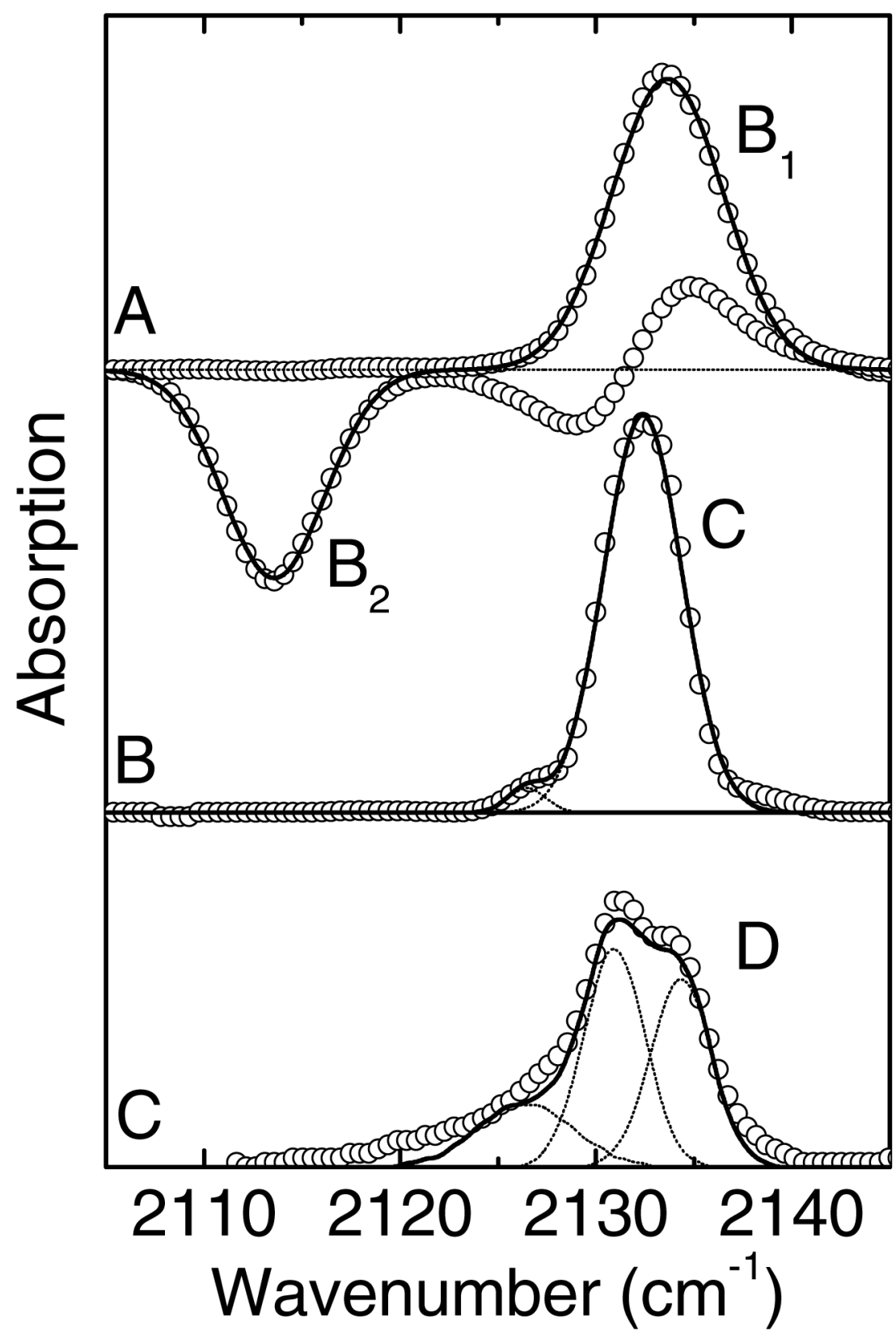

FIGURE 7.

Photoproduct spectra of CO molecules trapped at (A) the primary docking site B (2114/2133 $\left.\mathrm{cm}^{-1}\right)$ and in secondary sites (B) C (2126/2132 $\left.\mathrm{cm}^{-1}\right)$ and (C) D (2131/2134 $\left.\mathrm{cm}^{-1}\right)$ of wild-type $\mathrm{HbI}$. Dotted lines mark the individual bands obtained from Gaussian fits, solid lines give the sum. 


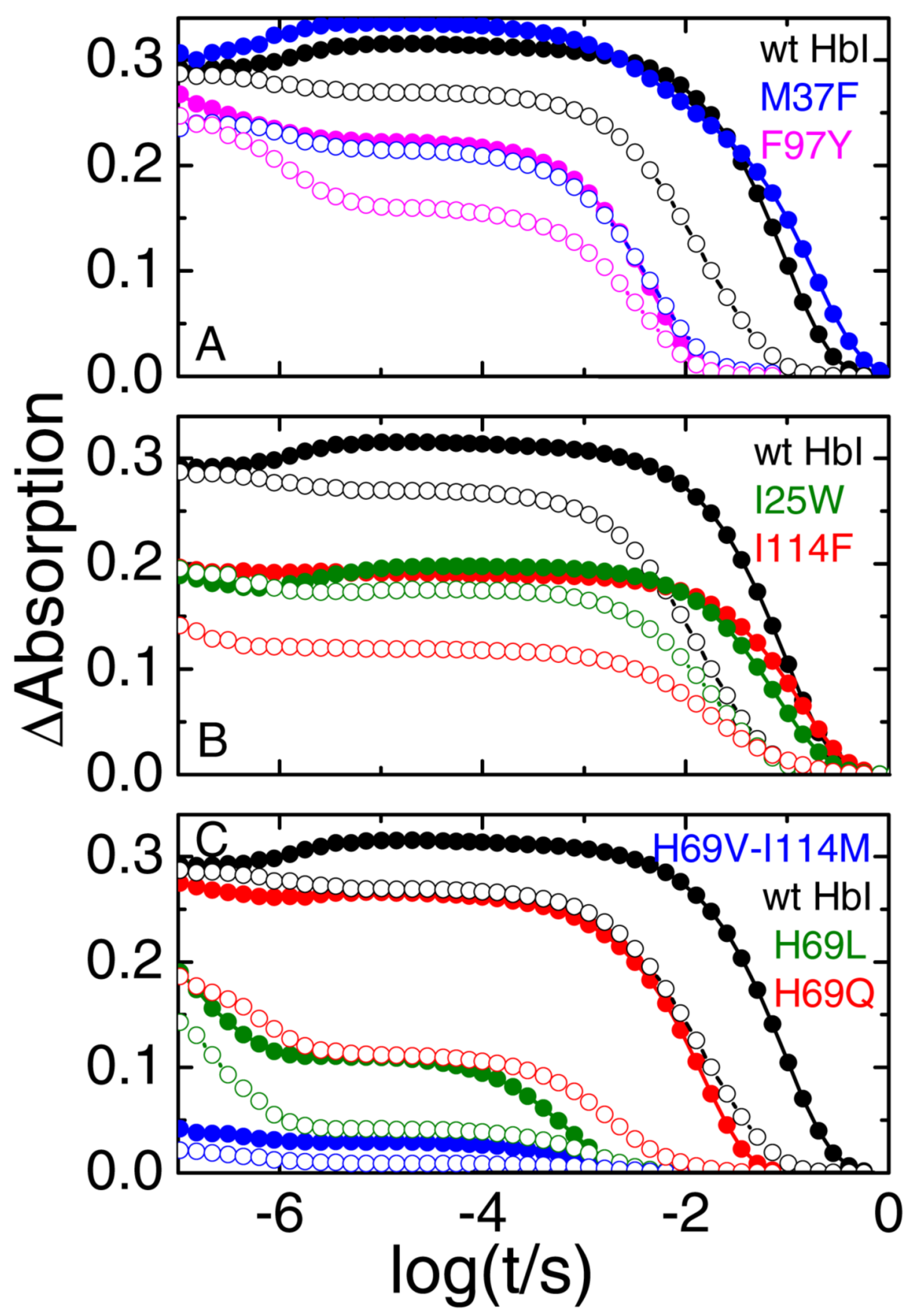

FIGURE 8.

Flash photolysis kinetics of wild-type and mutant HbICO samples dissolved in buffer, $\mathrm{pH} 8$ (closed symbols) and 75\%/25\% (vol./vol.) glycerol/buffer (open symbols), equilibrated with 0.05 bar CO. The absorption changes were monitored at $436 \mathrm{~nm}$ and $290 \mathrm{~K}$. (A) wild-type and mutants M37F, F97Y, (B) wild-type and mutants I25W, I114F, and (C) wild-type and mutants H69V-I114M, H69L, H69Q. 


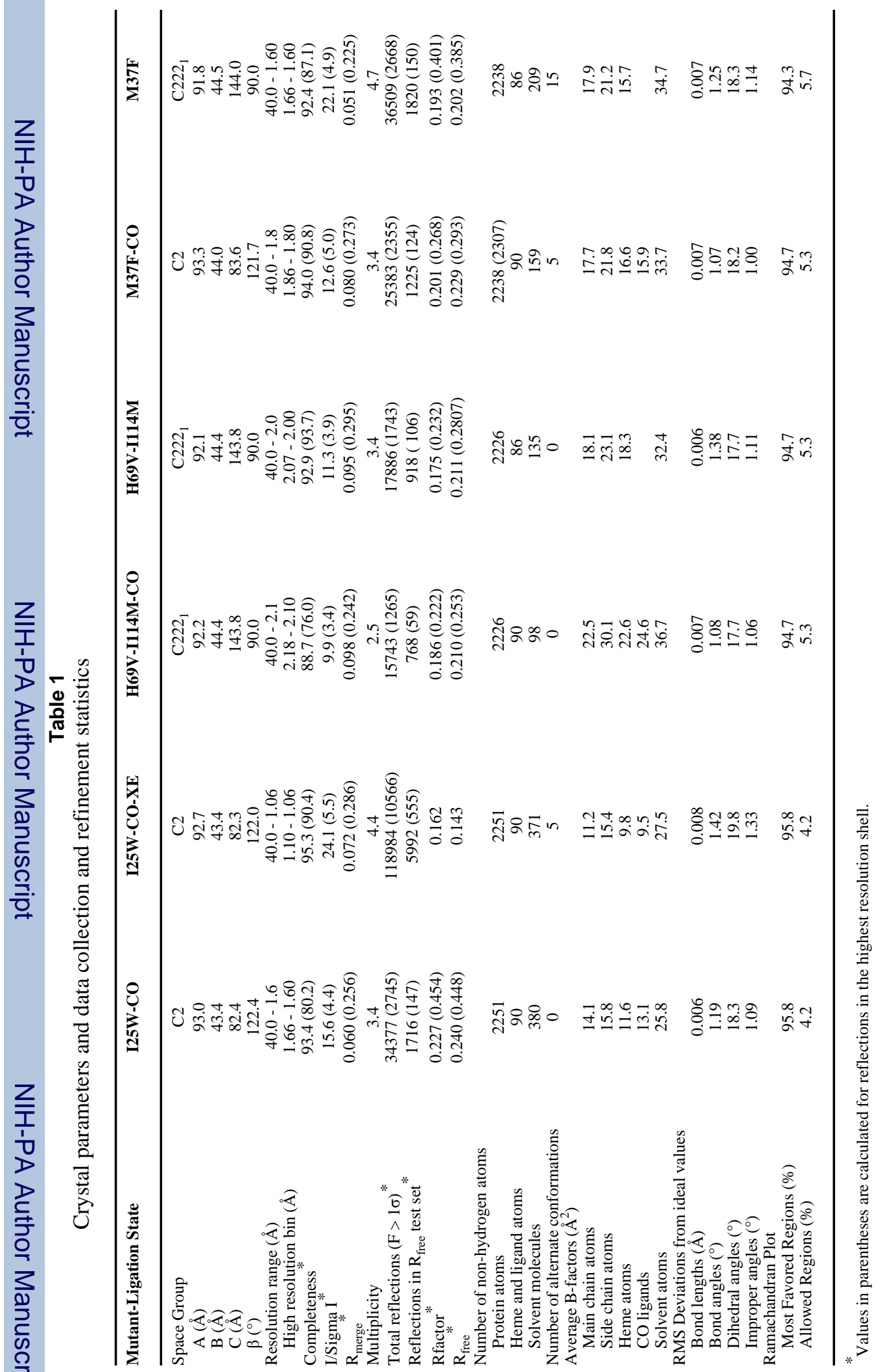


Table 2

IR band frequencies of heme-bound and photodissociated $\mathrm{CO}$ of $\mathrm{HbI}$ mutants at $4 \mathrm{~K}$, determined after $1 \mathrm{~s}$ illumination at $4 \mathrm{~K}$. Estimated experimental error: $\pm 0.5 \mathrm{~cm}^{-1}$. Values in parentheses denote fractional populations (in \%)

\begin{tabular}{|c|c|c|c|}
\hline Sample & $\mathbf{p H}$ & v(heme-bound CO $\left(\mathrm{cm}^{-1}\right)$ & $v\left(\right.$ photodissociated CO $\left(\mathrm{cm}^{-1}\right)$ \\
\hline Wild-type $\mathrm{HbI}$ & 4.0 & $1955(94), 1974(6)$ & $2121(16), 2125(42), 2128(42)$ \\
\hline Wild-type $\mathrm{HbI}$ & 7.2 & $1948(97), 1964(3)$ & $2114(14), 2133(86)$ \\
\hline $\mathrm{I} 25 \mathrm{~W}$ & 7.6 & $1948(95), 1964(5)$ & $2114(15), 2134(85)$ \\
\hline M37F & 8.0 & $1940(72), 1965(28)$ & $2116(26), 2129(17), 2141(44)$ \\
\hline H69L & 7.5 & $1971(100)$ & $2121(23), 2126(67)$ \\
\hline H69Q & 7.5 & 1945 (12), $1957(82), 1971(6)$ & $2120(26), 2126(35), 2130(26), 2139(13)$ \\
\hline H69V-I114M & 7.6 & $1989(9), 1967$ (10) 1977 (81) & $2123(72), 2131(28)$ \\
\hline F97Y & 7.8 & $1946(92), 1952(8)$ & $2114(12), 2135(75), 2141(13)$ \\
\hline $\mathrm{I} 114 \mathrm{~F}$ & 7.8 & $1944(97), 1963$ (3) & $2115(27), 2133(73)$ \\
\hline
\end{tabular}




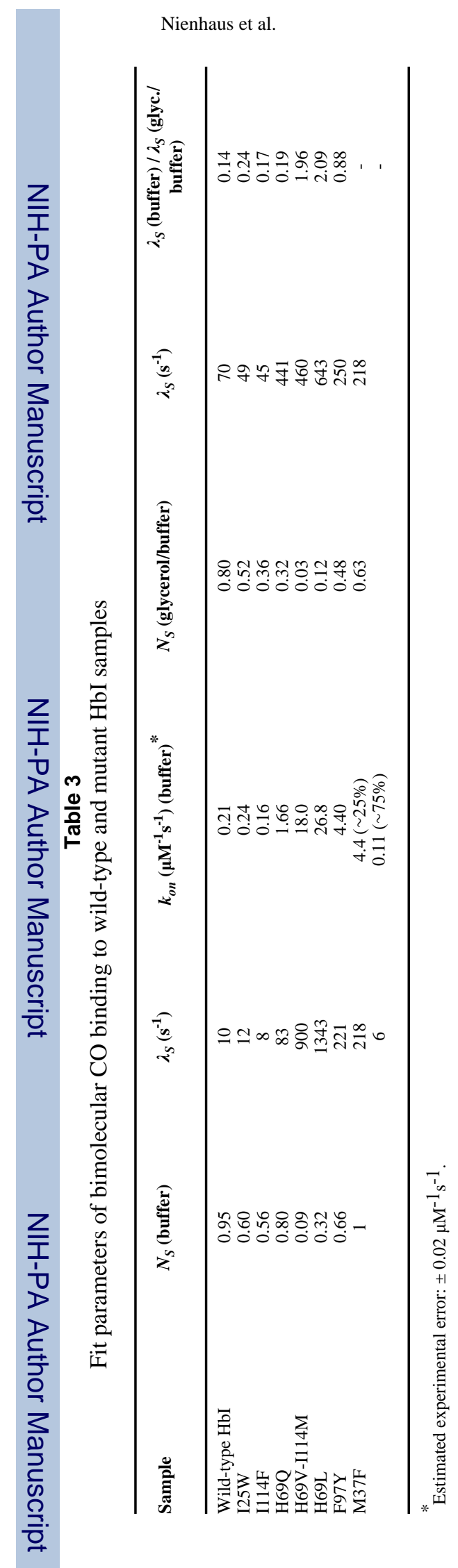

Page 30 
Table 4

Hill parameters of the oxygen affinity of $\mathrm{HbI}$ mutants

\begin{tabular}{lcc}
\hline Sample & P50 (torr) & Hill Coefficient \\
\hline Wild-type HbI $^{*}$ & 10.4 & 1.45 \\
I25W & 5.0 & 1.6 \\
M37F & 1.2 & 1.6 \\
H69Q & 70 & 1.3 \\
I114F & 21 & 1.08 \\
\end{tabular}

* Values taken from (39). 